\title{
The evidence for a temporal processing deficit linked to dyslexia: A review
}

\author{
MARY E. FARMER and RAYMOND M. KLEIN \\ Dalhousie University, Halifax, Nova Scotia, Canada
}

\begin{abstract}
The existence of a phonemic deficit that is predictive of, and probably causal to, many cases of reading difficulty is well established. Tallal (1984) has suggested that this phonemic deficit is in fact a symptom of an underlying auditory temporal processing deficit. Our purpose in this paper is to evaluate the plausibility of this hypothesis. The various components that might constitute sequential (or temporal) processing are described. Our review of the literature reveals considerable evidence for a deficit in dyslexics in stimulus individuation tasks (e.g., gap detection) and temporal order judgments in both the auditory and visual modalities. The possibility that a general temporal processing deficit is associated with dyslexia, as suggested by Tallal (1984), is explored, and possible etiologies for such a deficit are discussed. The possibility of a causal link between temporal processing deficits and some reading disabilities is demonstrated, and converging evidence from morphological studies is reviewed. It is concluded that a temporal processing deficit does appear to be present in many developmental dyslexics, and strategies are suggested for further research aimed at evaluating the hypothesis that this deficit may be the root cause of a number of cases of dyslexia itself.
\end{abstract}

The hypothesis that a temporal processing deficit may have a causal relationship with many cases of dyslexia has been gaining popularity in recent years. Findings from research in diverse areas have appeared to support this hypothesis. Clearly it is time to critically review the evidence available and to determine whether in fact the temporal processing deficit hypothesis has sufficient credibility to warrant further exhaustive investigation.

In this article we critically examine the claim that the phonemic/phonological impairment in dyslexia is caused by a more general underlying deficiency in the temporal processing of rapidly presented auditory stimuli (Tallal, 1984). We begin by briefly reviewing the evidence for a phonemic and/or phonological deficit, believed causal to many cases of developmental reading disability. We then review the evidence for a rapid temporal processsing deficit in both the visual and auditory modalities. These data are related to several components of temporal processing, notably to judgments of stimulus individuation, temporal order, and sequence discrimination. Data from motor se-

Portions of this work were included in a doctoral dissertation presented by the first author. The work was supported by a Natural Science and Engineering Research Council (NSERC) grant to the second author, and by an NSERC Graduate Scholarship and a Killam Memorial Scholarship awarded to the first author. The authors gratefully acknowledge the ideas and discussions contributed by Susan Bryson early in this paper's conception, as well as further helpful contributions by Dennis Phillips. The helpful and critical comments on earlier versions of this manuscript by Randi Martin, Richard Olsen, Paula Tallal, and several anonymous reviewers have been very much appreciated. Finally, the careful and constructive suggestions of Jim Neely were crucial in refining this paper and are acknowledged with gratitude. Requests for reprints should be addressed to R. M. Klein, Department of Psychology, Dalhousie University, Halifax, NS, Canada B3H 4J1 (e-mail: farmer@ac.dal.ca or klein@ ac.dal.ca). quencing tasks are also discussed. We explore and reject the idea that temporal processing deficits simply reflect an attentional disorder; we consider the implications of the heterogenous nature of dyslexia and the possible developmental course of the temporal processing deficit for studies in this field. Converging evidence from morphological and electrophysiological studies is reviewed. We conclude that there is sufficient evidence from a variety of paradigms for an association between dyslexia and temporal processing deficits to warrant further investigation of the claim that a general temporal processing deficit may underlie some cases of reading disability. Finally, we consider the plausibility of the temporal processing deficit as a cause of some reading disabilities and outline several ways to evaluate this hypothesis.

\section{A Note on Sampling Heterogeneity}

Before beginning our review of the evidence, we should emphasize that it is clear that a temporal processing deficit (or any other specific deficit, for that matter) will not be found to account for all cases of developmental dyslexia. Learning to read calls upon many cognitive processes and involves many areas of the brain. A breakdown in any of the contributing processes or areas may thus lead to an inability to learn to read in the normal way. A difficulty in learning to read, or dyslexia, should not be viewed as a condition in itself, but as a symptom of a breakdown in one or more of the various processes involved. To what degree, if any, a temporal processing deficit may contribute to reading disabilities remains to be demonstrated.

Considerable research has been conducted over the past few years in an effort to identify specific subtypes of dyslexic children, to see whether some skills deficits are evident in all reading-disabled children, or whether different 
dyslexics display different patterns of impairments. In 1971, Boder identified three groups of dyslexics: dysphonetic dyslexics (the largest group), who had great difficulty in applying grapheme-phoneme correspondence rules, and thus in reading nonwords; dyseidetic dyslexics, who could sound out words phonemically, but had great difficulty reading irregular words correctly; and a mixed dysphonetic-dyseidetic group. Some investigators have identified groups that are similar to one or more of Boder's three groups (e.g., Freebody \& Byrne, 1988; Johnson \& Myklebust, 1967; Lyon, 1985; Satz \& Morris, 1981). More recently, Castles and Coltheart (1993) have suggested that at least two varieties of developmental dyslexia can be identified and that these correspond approximately to the phonological and surface varieties identified in acquired dyslexia. The phonological dyslexics have difficulty in reading unfamiliar words and nonwords, but relatively better ability at reading irregular words. Surface dyslexics, on the other hand, are relatively worse at reading irregular words. A majority of subjects studied by Castles and Coltheart (1993) appeared to have mixed deficits; nevertheless, fully one third had a relatively pure deficit. In a replication and extension of this study, Seidenberg and Manis (1994) also found some relatively pure phonological and surface dyslexics. Moreover, because the surface developmental dyslexics' performance on tasks used to tap orthographic and phonological knowledge was similar to that of reading-matched controls, this pattern was characterized as a developmental delay. In contrast, the performance of phonological dyslexics often differed from that of both control groups on these tasks, suggesting that a deviant pattern characterizes many subjects in this group.

Other investigators have identified profiles that they have classified differently, such as Bakker's (1979) L- and P-type dyslexics; the O, A, and S types of Doehring, Trites, Patel, and Fiedorowicz (1981); and Lovett's (1984) accuracy- and rate-disabled groups. As Fletcher (1985) has pointed out, there is considerable work to be done before reading-disabled children can be classified as belonging to a particular subtype. This work will be complicated by the evidence that reading disability subtypes evolve as time progresses (Hynd, 1992). In this respect, the knowledge contributed by single case studies may be invaluable. It is evident that there are many different expressions of a reading disability, and no one underlying cause will be found to account for such variety. It is also evident, however, that some types of impairment are shared by many dyslexics. The question of heterogeneity among reading-disabled children must be borne in mind when findings of studies with such children are considered. We will further discuss the question of heterogeneity later in this paper.

\section{EVIDENCE FOR A PHONEMIC/PHONOLOGICAL DEFICIT ${ }^{1}$ IN DYSLEXIA}

Research in the last decade or so has provided ample evidence that dyslexics have problems with phonological processing (Liberman \& Shankweiler, 1985; Mann, 1984;
Stanovich, 1986a; Vellutino \& Scanlon, 1987). Indications are that a phonemic-/phonological-specific deficit is causal to reading disability (Bradley \& Bryant, 1978, 1983; Stanovich, 1988a; Stanovich, Cunningham, \& Cramer, 1984; Wagner, 1986), although reading skills contribute reciprocally to the development of phonological skills (Wagner \& Torgesen, 1987). Other well-documented differences between dyslexics and normal readers (e.g., in verbal memory, syntax, or semantics) may be the result of early difficulties with phonological coding (Jorm, 1983; Share \& Silva, 1987). In fact, Stanovich has suggested that poor readers are the victims of what he calls the "Matthew effect": ${ }^{2}$ an initial processing difficulty causes them to fall farther and farther behind as the demands on their skills increase, whereas proficient readers get better and better as they practice the skills they have learned (Stanovich, 1986b, 1988b).

Most researchers agree that this initial processing difficulty consists of a deficit in rapid and accurate phonological coding. The phonemic/phonological abilities of dyslexics have been investigated with the use of a wide variety of tasks, and results consistently reveal poor group performance relative to that of normal readers (Torgesen, 1985). For example, poor readers have difficulty in attempting to produce names in response to pictures or verbal definitions of objects (Snowling, van Wagtendonk, \& Stafford, 1988), and phonemic errors are common in the names that they do produce (Katz, 1986). Poor readers are also slower than normal readers in rapid naming tests of common objects, letters, digits, and colors (Bowers \& Swanson, 1991; Denckla \& Rudel, 1976; Fawcett \& Nicholson, 1994; Katz \& Shankweiler, 1985; Lovett, 1984, 1987; Mann, 1984; Wolf, 1986, 1991; Wolf \& Obregon, 1992). Poor readers cannot generate as many rhyming words as can normal readers, and they are slower when they do produce them (Snowling, Stackhouse, \& Rack, 1986). They also do not show the phonemic confusability effect (i.e., better memory for phonemically dissimilar vs. rhyming words) that is evident at an early stage in normal readers (Byrne \& Shea, 1979; Jorm, 1983; Mann, Liberman, \& Shankweiler, 1980), although the effect may emerge in poor readers in early adolescence (Johnston, 1982; Siegel \& Linder, 1984). Normal readers show a reduction in phonemic confusability with increasing age, probably because of increased precision of phonemic discrimination (Olson, Davidson, Kliegl, \& Davies, 1984). Finally, phoneme segmentation and awareness tasks, as well as rhyming skill, have been shown not only to differentiate good and poor readers (Bradley \& Bryant, 1983; Mann, 1984; Share, Jorm, Maclean, \& Matthews, 1984; Snowling et al., 1986; Stanovich, 1988a; Wagner \& Torgesen, 1987), but also to be good predictors of future reading ability (Adams, 1990; Goswami, 1990; Mann, 1993; Mann \& Brady, 1988; Share et al., 1984; Stanovich et al., 1984).

In many cases, poor reading seems to be a familial trait (Pennington \& Smith, 1988; Scarborough, 1989; Snowling, 1991). Early evidence suggested that when phonological and orthographical coding skills are considered, 
the phonological coding deficit in dyslexics is the more highly heritable (Olson, Wise, Conners, Rack, \& Fulker, 1989), with orthographic, or word-specific, coding ability being only weakly related to phonological coding ability in disabled readers. However, a recent large-scale study with monozygotic and dizygotic twin pairs with at least one reading-disabled member has provided evidence that both the phonological coding and orthographic coding abilities are substantially heritable and are genetically linked to phonemic awareness deficits (Olson, Forsberg, \& Wise, 1994).

Visual, or whole-word, coding may in some cases be highly developed in reading-disabled children, as an attempt to compensate for their phonemic deficit. As Frith (1986) has pointed out, when one component of the developing reading process is dysfunctional, other skills will likely become highly developed in compensation. Evidence that some dyslexics are more reliant on visual, or orthographic, coding in reading-related tasks comes from several sources (Aaron, 1985; Foorman \& Liberman, 1989; Gordon, 1984; Katz, Healy, \& Shankweiler, 1983; Rack, 1985; Underwood \& Boot, 1986; and see review by Snowling, 1991). For example, Rack (1985) presented dyslexics and reading-matched controls with a word to cue their recall of a previously paired word. The target word was orthographically similar to the cue word, and/or rhymed with it, or was unrelated (e.g., shoot: boot, fruit, foot, and butter). The dyslexics remembered more of the orthographically cued words than did their reading-matched controls, but fewer of the rhyme-cued words, regardless of whether presentation was auditory or visual. This suggested that they were using an orthographic strategy to a much greater degree than their reading-matched controls. Similarly, Gordon (1984) found that dyslexics tend to use a visual strategy when reading. He presented the letters $c, a$, and $t$ on a revolving drum, such that they could be read sequentially, as $a-c-t$, or spatially, as $c-a-t$. Gordon found that whereas non-reading-disabled relatives of the dyslexics were likely to read the sequentially presented $a-c-t$, dyslexics tended to read $c-a-t$, the spatial presentation.

In brief, there is now considerable evidence, as outlined above, for the existence of a phonological deficit in many dyslexics. Indeed, many researchers agree that dyslexia is fundamentally a linguistic problem, involving a deficit in rapid and accurate phonological coding (Brady, Mann, \& Schmidt, 1987; Katz et al., 1983; Katz, Healy, \& Shankweiler, 1984; Katz, Shankweiler, \& Liberman, 1981; Liberman, 1989; Vellutino, 1987). In fact, some researchers have advocated that dyslexia is a specifically linguistic problem, as speech and language are viewed as distinct human processes that are fundamentally different from other basic sensory systems such as those invoked for nonlanguage auditory processing (e.g., Liberman, 1989; Vellutino, 1987). Those supporting this view would maintain that the deficits seen in dyslexics for processing phonological stimuli should not be found when nonspeech stimuli are used. However, if the phonemic deficit evidenced in dyslexics has a more fundamental temporal basis, these poor read- ers should show a deficit in tasks using nonspeech sounds that are temporally comparable to speech sounds.

Hypotheses that proposed a nonlinguistic basis for dyslexia were in vogue earlier, but over the past decade they have been largely dismissed (see the review by Stanovich, 1986a). However, sufficient evidence has accumulated to question this dismissal, and to again raise the possibility of a more fundamental perceptual deficit. The difference now is that the existence of a phonemic/phonological deficit is not under debate. Rather, its causal primacy is increasingly being questioned.

Tallal (1984; Tallal \& Curtiss, 1990) has contended that the phonemic deficit is a symptom of a more general deficit in processing rapid temporal sequences. Support for Tallal's claim that there is a general deficit in processing rapid temporal sequences comes from both the visual and auditory modalities, as measured by tasks involving one or more aspects of sequential processing. There is also some evidence that a temporal processing deficit may contribute to the difficulties that dyslexics display on some motor tasks, and this will be discussed briefly later in this article. There is as yet no convincing evidence for a causal link between a temporal processing deficit and dyslexia, although evidence on this issue is growing rapidly. At the end of this review, we will outline some strategies that might be focused on this question. Before presenting the evidence in the auditory and visual modalities, we briefly discuss what is meant by sequential, or temporal, processing.

\section{REVIEW OF THE EVIDENCE FOR TEMPORAL PROCESSING DEFICITS IN DYSLEXICS}

\section{Analysis of Sequential Processing}

Sequential processing is a term that has been loosely used in the literature to describe any processing procedure involving two or more stimuli presented nonsimultaneously. However, this general rubric includes many different processing requirements and stimulus dimensions. In an attempt to better understand the data on dyslexics, we have broken down "sequential processing" into a logical sequence of the progressively more complex processes that might be said to fall under this rubric. In so doing, we have used and expanded upon the framework of Hirsh and Sherrick (1961) as a way of conceptualizing the components. The data on dyslexics reviewed below will be considered from this perspective.

Successful performance on any task involving two or more stimuli depends first on the ability to detect (and perhaps to identify) the presence of a single stimulus. Given that such detection is within normal limits, we can then consider the various components involved in processing a sequence of stimuli. According to Hirsh and Sherrick (1961), there are at least two basic components of temporal, or sequential, resolution. The first is the introduction of a minimum time interval between two events or stimuli so that the two are perceived as just barely sequential, or nonsimultaneous. Determination of this minimum time has been 
called the separation threshold method (DiLollo, Hanson, \& McIntyre, 1983). This aspect of temporal processing might be called stimulus individuation, that is, the determination of whether one or more than one item has been presented. The stimuli involved may be auditory, visual, or tactile, and thus the duration of the interstimulus interval (ISI) may be said to be an amodal property. Similarly, the stimuli involved in both detection of a single stimulus and stimulus individuation may vary along amodal dimensions such as location and duration, a matter to which we will return later.

Within each modality, stimuli may vary along dimensions that give them an identity peculiar to that modality, such as color for visual stimuli, or pitch for auditory stimuli. Attaching identities to stimuli is essential for the determination of temporal order, which Hirsh and Sherrick (1961) have identified as the second component of sequential resolution. For a judgment of temporal order to be made, the two stimuli must differ along some dimension that confers an identifiable property to each. Thus, temporal order judgment is necessarily a more complex operation than stimulus individuation, for which the stimuli need not differ in any modal property. Of course, determination of the order of two stimuli presupposes that the subject can discriminate the two stimuli (can determine whether they are the same or different), and this might be seen as a prerequisite for temporal order judgment decisions.

Finally, an even more complex task is that of judging the order of a series of sequentially presented stimuli. Although this might appear to differ only quantitatively from the task of judging temporal order, we consider it a separate component of sequential processing because of the exponentially greater demands placed on processing resources as the number of stimuli increases. Such tasks usually require that pairs of sequences of stimuli be matched. In these tasks, as well as those requiring reproduction of the order of a series of stimuli, a memory component is added to the perceptual requirements.

Thus the processing of sequential stimuli may involve four basic components: detection (or identification) of a single stimulus event, determination of stimulus individuation, temporal order judgments, and sequence matching or discrimination. These four components may also involve variations along different stimulus dimensions, including location, duration, and identity.

Evidence in dyslexics for (and against) a deficit in each component in both the visual and auditory modalities is considered below. Studies have been presented, for ease of reference, in tables grouped according to the component of sequential (temporal) processing involved. Comparisons across studies must be tempered by consideration of numerous methodological differences. These include the criteria used for subject selection, the age range of subjects, type and duration of stimuli, mode of stimulus presentation, differential memory demands, and type of response required. In particular, it is not always clear that the disabled readers would meet the generally accepted criteria for dyslexia, although in the majority of cases this would be so. For the reader's benefit, the terminology employed in the orig- inal study (e.g., poor readers, specific reading-disabled children) has been used when first describing each study.

Before beginning this review, we conducted an extensive search of the vast literature on dyslexia, ${ }^{3}$ and we have endeavored to include all the studies that might bear on the question of whether a temporal processing deficit might contribute to reading disability. Some studies with languageimpaired children will also be described later when we evaluate this hypothesis (but are not included in the review or tables). Much of Tallal's work (including her early studies) has involved language-impaired children. It was the apparent strong link between language impairment and reading disability that led Tallal to propose the temporal processing deficit hypothesis as contributing to both disorders, which she views as possible different points on the same continuum (Tallal \& Curtiss, 1990). The link between early language difficulties and later reading disorder is firmly established (Beitchman \& Inglis, 1991; Kamhi \& Catts, 1989; Rapin \& Allen, 1988; Scarborough, 1990; Stanovich, 1986a; Stark, Bernstein, Condino, Bender, Tallal, \& Catts, 1984; Tallal, 1988), even in instances in which language difficulties have not been diagnosed in early childhood (Gibbs \& Cooper, 1989; Kamhi \& Catts, 1986). This link will be further explored later in this review. However, in including in this paper some of the work with languageimpaired children, we do not wish to imply that all languageimpaired children will be reading-disabled (although most will be), or that all reading-disabled children have (or have had) language impairments. Clearly there are cases of reading impairment without apparent language difficulties (see, e.g., Aaron, Olsen, \& Baker, 1985), and of reading-disabled children without temporal processing difficulties (e.g., Tallal \& Stark, 1982).

As with any review of this nature, the reader should bear in mind the perennial problem that since null results are less likely to be published than positive findings, the literature itself carries an inherent bias when any hypothesis is being evaluated. With these cautions in mind, we present our review.

Detection or identification of a single stimulus. Detection may involve simple judgments about the presence or absence of a stimulus, or it may involve more complex judgments about the duration, location, or identity of a stimulus. The latter judgments involve discrimination in addition to detection. Discrimination is a prerequisite for the more demanding judgments (such as temporal order) to be discussed later. Simple detection may be tested by asking a subject to report the presence or absence of a click or tone or of a light flash, after a cue. Variations that go beyond the simple auditory or visual detection task might involve duration judgments, like those required in adjusting the duration of a stimulus to match the duration of a test stimulus. Location judgments might require that subjects indicate the ear to which an auditory stimulus has been presented, or localize a sound along an arc. In the visual modality, the subject might judge whether a flash has been presented to the left or right of a fixation point. Identity can also be used as a variable; identity judgments might be made about the pitch of a tone, the color of a 
light flash, or the identity of a letter or digit. In such cases, identity is a modality-specific attribute, although identification can also involve amodal properties such as the duration of a stimulus.

Studies involving the detection or identification of a single stimulus are presented in Table 1. Most studies used visual stimuli and required motor responses, but age of subjects, criteria for subject selection, and type and duration of stimuli all varied considerably. As can be seen from Table 1, there is little evidence in the literature that dyslexics have difficulty in either detecting or identifying a single stimulus. Only one study (Gross-Glen \& Rothenberg, 1984) has reported a significant deficit in detection/ identification of simple visual stimuli among readingimpaired individuals. In that study, dyslexics 11-15 years of age required a longer stimulus exposure than did controls to identify single or double letters presented monocularly. Normal readers could identify one of four letters with $62 \%$ accuracy with exposures of less than $25-\mathrm{msec}$ duration. Dyslexics required significantly longer as a group to reach this criterion: Mean duration thresholds (and standard deviations) for identification of a single letter from a set of four presented to the left or right visual field was, respectively, $41.4(50.1)$ and $35.0(47.6) \mathrm{msec}$ for dyslexics, and 8.6 (4.7) and 7.6 (4.3) msec for normal readers.

A notable difference between the Gross-Glen and Rothenberg (1984) study and those yielding negative effects is that the former researchers presented the stimuli monocularly (to the dominant eye), to one side or the other of a central fixation point. Thus the stimuli had to be detected peripherally ( $2^{\circ}$ visual angle from the fixation point) rather than foveally, unlike those in the other studies described below. Accuracy for identifying stimuli such as letters does decrease as retinal eccentricity is increased. The evidence for a differential impairment in dyslexics is unclear. It has been suggested that normal readers can more accurately identify letters that are in close proximity than can dyslexics (but not when the letters are farther apart)
(Geiger \& Lettvin, 1987). However, when single letters are presented at varying eccentricities around a fixation point, dyslexics have been found to perform as well as good readers (Klein, Berry, Briand, D'Entremont, \& Farmer, 1990). In the Klein et al. study, each stimulus was presented very briefly $(17 \mathrm{msec})$. All subjects were less accurate at identifying the stimulus as eccentricity increased, but the dyslexics were no worse than the controls. It may be that the added methodological difference of presenting the stimuli to only one eye in the Gross-Glen and Rothenberg study contributed to an explanation for the anomalous results found, although it is not clear why this might be so. It seems unlikely that the brevity of the exposure time per se contributed to their results, given the Klein et al. findings. It is also unlikely that the severity of the dyslexia contributed to the results, because dyslexics in the GrossGlen and Rothenberg study and those in the Klein et al. study were very similar, both in reading level and in source. One difference between these two studies was in the age of the dyslexics; those in the Klein et al. study were on the average 3 years older than those in the Gross-Glen and Rothenberg study. However, the dyslexics in the Tallal (1980) study described below were considerably younger, and they were not impaired when detecting stimuli. Without further study, the critical difference between GrossGlen and Rothenberg's study and the others reviewed in this section cannot be determined

Other studies have revealed no differences between good and poor readers in their detecting or identifying of single stimuli. Mason (1980) found no differences between good and poor college readers who identified letters exposed for various durations from 20 to $130 \mathrm{msec}$. In addition, Blackwell, McIntyre, and Murray (1983) reported that learningdisabled children were equivalent to controls in detecting and recognizing a single letter ( $\mathrm{T}$ or $\mathrm{F}$ ) displayed for $150 \mathrm{msec}$. Finally, Tallal (1980), using brief tones, found no significant differences between dyslexics and controls detecting, or discriminating between, stimuli or learning the correct motor response.

Table 1 Studies Involving Detection or Identification of a Single Stimulus

\begin{tabular}{|c|c|c|c|c|c|c|c|c|}
\hline Study*+ & $\begin{array}{c}\text { Age } \\
\text { Range } \\
\text { (Years) }\end{array}$ & $N$ & $\begin{array}{l}\text { Selection } \\
\text { Criteria }\end{array}$ & Stimuli & $\begin{array}{l}\text { Visual/ } \\
\text { Auditory }\end{array}$ & $\begin{array}{l}\text { Stimulus } \\
\text { Duration }\end{array}$ & $\begin{array}{l}\text { Response } \\
\text { Required }\end{array}$ & $\begin{array}{c}\text { Group } \\
\text { Differences } \\
\text { Found? }\end{array}$ \\
\hline $\begin{array}{l}\text { Blackwell } \\
\text { et al. (1983) }\end{array}$ & $8.2-12.8$ & 17 & A & single letter & V & $150 \mathrm{msec}$ & verbal & no \\
\hline $\begin{array}{l}\text { Gross-Glen \& } \\
\text { Rothenberg (1984) }\end{array}$ & $11-15$ & 16 & B & single letter & $\mathrm{V}$ & $M=2-180 \mathrm{msec}$ & verbal & yes \\
\hline Klein et al. (1990) & $13.1-18.1$ & 13 & $\mathrm{C}$ & single letter & V & $17 \mathrm{msec}$ & verbal & no \\
\hline Mason (1980) & college age & 8 & D & single letter (of 4) & V & $20-130 \mathrm{msec}$ & motor & no \\
\hline Tallal (1980) & $8.5-12$ & 20 & $\mathrm{E}$ & complex tones & $\mathrm{A}$ & $75 \mathrm{msec}$ & motor & no \\
\hline
\end{tabular}

*With the exception of the Tallal (1980) study, in which 8.5-year-old children were used as controls, and the Klein et al. (1990) study, in which good and poor college-age readers were used, all studies employed age-matched normal readers as controls. $\dagger$ The Reed (1989) study, in which dyslexics were impaired in identifying single phonemes, was not included, because these were not considered to be single stimuli for the purposes of this study. $\$ \mathrm{~A}=$ At least a 1.5 -year discrepancy between any Wide Range Achievement Test subtest and expected grade placement based on chronological age; $B=1$ to 6 years behind ageappropriate grade levels, based on Gray Oral Reading Test scores; $\mathrm{C}=$ At least 2 years below expected grade level, based on Slosson Reading Test; $\mathrm{D}=$ Scoring at 11-40th percentiles on Nelson-Denny Reading Test; $\mathrm{E}=$ Formal diagnosis of specific reading delay; reading at least 1 year below chronological age grade placement as measured by Metropolitan Reading Test. 
Dyslexics have been shown to be impaired in the identification of single phonemes in the middle of the continuum, near the phoneme boundary (see, e.g., Reed, 1989). However, these results have not been included in the tables, since for the purposes of this discussion such phonemes are not regarded as single stimuli, but as a series of rapidly changing acoustic events (the spectral changes of the formant transitions).

Thus, the consensus appears to be that dyslexics do not have difficulty in detecting, or even identifying, a single stimulus. As will be seen from the section on discrimination of sequences, below, they also may not have difficulties when a number of stimuli are presented simultaneously so that the stimuli can be viewed as a single entity or pattern, or when the stimuli are presented relatively slowly sequentially. However, as can be seen in the following sections, when temporally ordered stimuli must be processed rapidly, dyslexics may have difficulties when the temporal intervals are very brief.

Individuation of two stimuli. Tasks that involve the determination of stimulus individuation take one of several forms. Fusion tasks determine the minimum interstimulus interval (ISI) at which subjects are able to perceive that there are two identical stimuli, rather than one. Gap detection tasks determine the minimum ISI required for a subject to perceive that a stimulus has been interrupted by a temporal gap. Integration tasks determine the minimum ISI at which subjects perceive two nonidentical stimuli, rather than one integrated form.

Simple judgments of stimulus individuation may involve two identical brief stimuli presented in the same location, separated temporally by an ISI. Stimuli may be auditory (e.g., clicks or tones) or visual (e.g., light flashes); tasks with such stimuli are known as auditory or visual fusion tasks. ${ }^{4}$ Such tasks might also involve stimuli of a longer duration, with different onset times. The shortest ISIs (or minimum separation thresholds) required by normal subjects in order to perceive two stimuli are much longer in the visual modality than in the auditory. In click fusion tasks, normal subjects can determine that two clicks have been presented with ISIs as low as $2-3 \mathrm{msec}$ (Albert \& Bear, 1974; Auerbach, Allard, Naeser, Alexander, \& Albert, 1982; Fay, 1966; Hirsh \& Sherrick, 1961). To be seen as separate by normal subjects, visual stimuli must have ISIs of some $20 \mathrm{msec}$ (Hirsh \& Sherrick, 1961). With subthreshold stimuli, it has been shown that for double light flashes, complete summation occurs with ISIs below $16 \mathrm{msec}$, and an ISI of $65 \mathrm{msec}$ is necessary before no summation occurs (Ripps \& Weale, 1976). Because resolution of the second stimulus can be assumed to be associated with the degree of summation, the time required for stimulus individuation judgments could be expected to be in this range.

Many of the studies involving stimulus individuation judgments have required subjects to detect the gap between two stimuli, rather than just judge that two stimuli were presented. In such cases, the interstimulus gap might be regarded as a third event that makes it apparent that two stimulus events, rather than one, have occurred. In order to detect the gap between two visual stimuli, normal adults require an ISI of 50-55 msec (DiLollo, Arnett, \& Kruk, 1982). In order to detect the gap between two auditory stimuli, normal adults require thresholds from approximately 5 to $16 \mathrm{msec}$ (depending on the frequency of the stimulus) (Werner, Marean, Halpin, Spetner, \& Gillenwater, 1992). It will be noted that in both modalities, the ISIs required for gap detection are longer than those required for stimulus individuation. For auditory stimuli, there is evidence that threshold or minimum ISIs decrease as intensity of tones increases. For visual stimuli, ISIs decrease for normal subjects as contrast increases. There is also an effect of spatial frequency, with threshold ISIs being lower at low spatial frequency (Slaghuis \& Lovegrove, 1985).

Stimulus individuation judgment tasks almost invariably involve stimuli presented in the same location. Presentation of identical stimuli in different locations requires judgments of nonsimultaneity rather than stimulus individuation and may involve the confound of apparent motion in both the visual and auditory modalities. There is a variation of the stimulus individuation task that involves nonidentical stimuli. This is the temporal integration of form task, and it introduces a spatial element. In this case, two dissimilar stimuli that occupy different parts of the same general location (such as the vertical and horizontal arms of a cross) are presented sequentially. The maximum ISI at which the stimuli are seen as a single form rather than as two separate stimuli is then determined (DiLollo et al., 1983).

There is considerable evidence in the literature that dyslexics are impaired in stimulus individuation tasks. Most of this evidence is in the visual domain, but a few auditory experiments exist also. Studies involving stimulus individuation determinations are presented in Table 2 . As can be seen, in these studies, ISIs and response requirements again differ, although the criteria for subject selection and the age ranges involved are more consistent than those in Table 1. The stimuli used, however, have varied greatly. Although this makes it difficult to compare studies, it does indicate that results showing a deficit on stimulus individuation tasks are stable across a variety of types of task.

Using two tones of $17-\mathrm{msec}$ duration, and ISIs from 0 to $40 \mathrm{msec}$, McCroskey and Kidder (1980) found that both a reading-disabled and a general learning-disabled group of 9-year-olds needed longer ISIs than did normals to separate the tones. The reading-disabled children were affected by intensity, but not frequency. Haggerty and Stamm (1978) used a click fusion task, but rather than present the two clicks sequentially to both ears, they presented them either to both ears simultaneously, or with one ear leading. Their learning-disabled group needed a longer ISI to separate clicks than did the controls $(1.67 \mathrm{msec}$ vs. $1.29 \mathrm{msec})$. Additionally, fusion intervals were highly correlated with consonant discrimination for the learning-disabled children. In this study, however, the results of the stimulus individuation task are confounded by the method of presenting the clicks to separate ears, which would introduce a spatial location cue. 
Table 2

Studies Involving Determination of Individuation

\begin{tabular}{|c|c|c|c|c|c|c|c|c|}
\hline Study* & $\begin{array}{l}\text { Age } \\
\text { Range } \\
\text { (Years) }\end{array}$ & $N$ & $\begin{array}{l}\text { Selection } \\
\text { Criteria } †\end{array}$ & Stimuli & $\begin{array}{c}\text { Visual/ } \\
\text { Auditory }\end{array}$ & $\begin{array}{l}\text { Stimulus } \\
\text { Duration }\end{array}$ & $\begin{array}{l}\text { Response } \\
\text { Required }\end{array}$ & $\begin{array}{l}\text { Group } \\
\text { Differences } \\
\text { Found? }\end{array}$ \\
\hline $\begin{array}{l}\text { Arnett \& DiLollo } \\
\text { (1979) }\end{array}$ & $7-13$ & 24 & A & $\begin{array}{r}\text { two } 25 \text {-dot } \\
\text { matrices }\end{array}$ & V & $\begin{array}{c}3-127 \mathrm{msec} \\
\text { (plotting interval) }\end{array}$ & motor & no \\
\hline $\begin{array}{l}\text { Badcock \& } \\
\quad \text { Lovegrove (1981) }\end{array}$ & $M=14.3$ & 12 & B & $\begin{array}{l}2 \text { sine-wave } \\
\text { gratings (gap or } \\
\text { grating in ISI) }\end{array}$ & V & $0-250 \mathrm{msec}$ & $\begin{array}{l}\text { verbal (to gap } \\
\text { detection) }\end{array}$ & yes \\
\hline DiLollo et al. (1983) & $8-14$ & 10 & $\mathrm{C}$ & vertical lines & V & varied & $\begin{array}{c}\text { motor (to gap } \\
\text { detection) }\end{array}$ & yes $\ddagger$ \\
\hline $\begin{array}{l}\text { Haggerty \& } \\
\quad \text { Stamm (1978) }\end{array}$ & $7-9$ & 19 & $\mathrm{D}$ & clicks & A & varied & verbal & yes \\
\hline $\begin{array}{l}\text { Lovegrove } \\
\text { et al. (1980) }\end{array}$ & 8 & 15 & E & $\begin{array}{l}2 \text { sine-wave } \\
\text { gratings (gap or } \\
\text { grating in ISI) }\end{array}$ & V & $125-325 \mathrm{msec}$ & $\begin{array}{l}\text { verbal (to gap } \\
\text { detection) }\end{array}$ & $\begin{array}{l}\text { yes (low spatial } \\
\text { frequencies) }\end{array}$ \\
\hline $\begin{array}{l}\text { McCroskey \& } \\
\text { Kidder (1980) }\end{array}$ & $7-9$ & 45 & F & 2 tones & A & $0-40 \mathrm{msec}$ & $\begin{array}{l}\text { motor } \\
\quad \text { (individual } 1 \\
\text { or } 2 \text { tones) }\end{array}$ & yes \\
\hline $\begin{array}{l}\text { O'Neill \& } \\
\text { Stanley (1976) }\end{array}$ & $M=12.37$ & 13 & G & 2 lines & $\mathrm{V}$ & $20-50 \mathrm{msec}$ & $\begin{array}{l}\text { verbal? } \\
\quad \text { (individual } 1 \\
\text { or } 2 \text { lines) }\end{array}$ & yes \\
\hline $\begin{array}{l}\text { Slaghuis \& } \\
\quad \text { Lovegrove (1985) }\end{array}$ & 9 & 12 & $\mathrm{H}$ & $\begin{array}{l}2 \text { square wave } \\
\text { gratings }\end{array}$ & V & varied & $\begin{array}{l}\text { verbal (to gap } \\
\text { detection) }\end{array}$ & yes \\
\hline $\begin{array}{l}\text { Stanley \& } \\
\text { Hall (1973) }\end{array}$ & $8-12$ & 33 & $\mathrm{I}$ & $\begin{array}{l}\text { "no," arms of } \\
\text { cross, cross in } \\
\text { square }\end{array}$ & $\mathrm{V}$ & $\begin{array}{l}100-155 \mathrm{msec} \\
170-365 \mathrm{msec}\end{array}$ & $\begin{array}{l}\text { verbal (of } \\
\text { separate stimuli) } \\
\text { verbal } \\
\quad \text { (identity of stimuli) }\end{array}$ & $\begin{array}{l}\text { yes } \\
\text { yes }\end{array}$ \\
\hline $\begin{array}{l}\text { Winters et al. } \\
\text { (1989) }\end{array}$ & $18-37$ & 8 & $\mathrm{~J}$ & $\begin{array}{c}\text { sides of a } \\
\text { square }\end{array}$ & $\mathrm{V}$ & varied & $\begin{array}{l}\text { verbal? } \\
\quad \text { (of simultaneous } \\
\text { or sequential } \\
\text { presentation) }\end{array}$ & $\begin{array}{c}\text { yes } \\
\text { (contiguous sides } \\
\text { no } \\
\text { (opposite sides) }\end{array}$ \\
\hline
\end{tabular}

Note-ISI, interstimulus interval. *All studies used age-matched normal readers as controls. ${ }^{\dagger} \mathrm{A}=$ Reading at least 1 year below grade level on basis of teacher evaluations and Stanford Achievement Test results; B = Mean reading lag of 4:8 on Neale Analysis of Reading Ability; $\mathbf{C}=$ At least 2 years lag in reading comprehension (based on Metropolitan Achievement Test and Wide Range Achievement Test scores) $\mathrm{D}=$ Learning-disabled classification (average IQ, substantial academic deficiencies); $\mathrm{E}=$ At least 2 years reading lag, based on Neale Analysis of Reading Ability; $\mathrm{F}=$ Average IQ, reading 2 years below grade level; $\mathrm{G}=\mathrm{A}$ reading disability of at least 2.5 years below chronologi$\mathrm{cal}$ age on a standard reading comprehension test; $\mathrm{H}=$ Mean reading delay of $2: 4$ years, measured on the Neale Analysis of Reading Ability; $\mathrm{I}=$ Specific reading disability of 2.5 years below normal (consultation with remedial teachers); $\mathbf{J}=$ All adults reading at 5 th -7 th grade level. \$See the discussion on amelioration at older ages in the section of the paper titled "The Developmental Course of Visual and Auditory Temporal Processing Deficits."

In the visual domain, Lovegrove and his colleagues have repeatedly found that specific reading-disabled children need longer ISIs than do controls to detect blanks between two sine-wave gratings, but only at low spatial frequencies (Badcock \& Lovegrove, 1981; Lovegrove, Heddle, \& Slaghuis, 1980; Slaghuis \& Lovegrove, 1985). (At high spatial frequencies, these findings were reversed, with normal readers needing longer ISIs.) In a stimulus individuation task employing two straight lines, 12-year-old dyslexics needed longer ISIs than controls did to reach $75 \%$ accuracy (ca. $45 \mathrm{msec}$ vs. $30 \mathrm{msec}$ ) (O'Neill \& Stanley, 1976). DiLollo et al. (1983) also used two sequentially presented straight lines with 8- to 14-year-old dyslexics and controls. In their experiment, one of each pair of test trials consisted of the two lines separated by varying ISIs, and the other consisted of a single straight line, matched for duration and brightness. The dyslexics as a group needed longer mean ISIs $(115 \mathrm{msec})$ to detect which of the two trials contained the blank than did the controls $(69 \mathrm{msec})$. It should be noted that 4 out of the 10 dyslexic subjects performed at a level equivalent to that for the controls. (These 4 included the three oldest subjects: all 4 were over 12 years of age.)

However, Arnett and DiLollo (1979) found no differences in performance between their controls and poor readers on a temporal integration task in which subjects were required to identify from which matrix (of two) 1 of 25 sequentially presented dots was missing. Arnett and DiLollo suggested that the failure to find significant differences between their good and poor readers on the temporal integration task indicated that differences found in previous studies, such as those of Stanley and Hall (1973; see below), might in fact be due to response-criterion differences (e.g., dyslexics may be more conservative in their responses). An alternative explanation might be that $\mathrm{Ar}$ nett and DiLollo failed to find a difference between their groups because their poor readers were not in fact truly reading disabled. Their subjects were selected on the basis of being at least 1 year below grade level in reading, and may thus have been less severely disabled than subjects in many of the other studies cited - a point that DiLollo et al. 
raised in their 1983 paper, in which the dyslexics studied were at least 2 years behind in reading.

Using a temporal-integration-of-form task, Stanley and Hall (1973) presented two parts of a stimulus with 20-msec duration and varying ISIs. To separate the two stimuli, dyslexics needed longer ISIs than did the normal readers (mean ISI of 140 vs. $102 \mathrm{msec}$ ), and to identify the stimuli, dyslexics needed $327 \mathrm{msec}$, as opposed to $182 \mathrm{msec}$ for the normal readers. In another temporal-integrationof-form task, adult dyslexics were found to have impaired sensitivity relative to controls when two parts of a stimulus were presented sequentially to adjacent retinal areas (Winters, Patterson, \& Shontz, 1989).

Thus, there is converging evidence, mostly in the visual domain, that dyslexics are impaired in stimulus individuation tasks that require temporal resolution. As can be seen from a comparison of Tables 1 and 2, group differences were found in only one study requiring detection of a single stimulus (when the stimuli were presented monocularly and peripherally), whereas group differences were found in nearly all tasks involving stimulus individuation judgments. However, the number of stimulus individuation studies, particularly in the auditory modality, is not large. Perhaps more noteworthy is the fact that a number of researchers have also found deficits for dyslexics in the more complex task of temporal order judgment (TOJ). Whether dyslexics who are impaired on TOJ tasks are necessarily also impaired on stimulus individuation tasks remains to be determined.

Temporal order judgment. The second sequential processing component outlined by Hirsh and Sherrick (1961) involves a judgment of temporal order. In order for a subject to make a temporal order judgment, the events must be identifiable as discrete elements, so that the subject is able to specify which came first. This can be done amodally, by varying either the duration or the location of the stimuli. In the latter case, the necessity of providing distinctive, identifiable stimuli is avoided, because the subject need only point to (or otherwise convey) the location of the leading stimulus. In this case, however, a spatial variable has been added to the basic perceptual task. When the spatial variable is omitted by presenting the stimuli in the same location, the question of identity of the stimuli has been added. This can be the amodal property of duration (such as long and short tones or flashes), or stimuli can be identifiable along a modality-specific dimension, such as frequency of tones (e.g., high and low) or color of light flashes (e.g., green and red).

Most of the studies comparing disabled readers with normal readers on temporal order judgment tasks have involved stimuli with modality-specific identities, although a very few have involved two stimuli presented in different locations. Rarely, a task has required that subjects determine whether two stimuli presented in rapid sequence were the same as each other, or different. Such tasks, which we might call matching tasks, necessitate the use of distinctive, identifiable stimuli, but do not carry the requirement for explicit ordering of the stimuli. The two stimuli must each be detected and the identities encoded, but the perception of order is not essential for a correct response. Studies involving matching tasks that have found dyslexics to be impaired versus controls are described here, but because no explicit ordering judgment is involved, they have not been included in the table with temporal order judgment task studies.

Tallal (1980) found dyslexics to be impaired in comparison with younger controls when they were required to say whether two tones presented in rapid succession, at ISIs of 8-305 msec, were the same or different. At ISIs of $428 \mathrm{msec}$, the dyslexics did as well as the controls. Although the disabled readers did make more errors in a temporal order judgment task than in the same-different judgment task, neither they nor the controls showed any statistically significant difference in performance on the two tasks. Thus, even when an overt ordering judgment was not required, the ISIs involved in the task were sufficiently short to preclude the dyslexics from correctly judging the similarity of the pairs. Reading group differences for same-different judgments involving pairs of differentfrequency tones were also found by De Weirdt (1988).

In addition to the findings with simple tone matching studies, dyslexics have also been found to be impaired when required to match more complex stimuli. Poor readers 7:9 to 10:4 years of age were found to be worse than good readers on same-different judgments for pairs of synthesized consonant-vowel syllables $(\mathrm{ba} / \mathrm{da}$ ) from a phoneme continuum (Reed, 1989). The stop consonants involve spectral changes in the time frame of tens of milliseconds, and any impairment in the ability to process the order of these changes would result in impaired discrimination of the sounds. De Weirdt (1988) found similar results for the discrimination of the phoneme pairs pa/ta, both in 9-yearold dyslexics and in 6-year-old prereaders who were shown to be relatively poor readers in later testing.

The studies that involve judgments of temporal order are listed in Table 3. Many of these studies were carried out with younger children, but again, criteria for subject selection and response requirements varied widely, as did ISIs and stimuli used.

In work with reading-disabled children, Tallal (1980) found the disabled readers to be impaired on a rapid auditory perception task that required temporal order judgments for high-low tones with short ISIs. Results on the temporal order judgment task correlated significantly with a number of reading measures; in particular, a correlation of .81 was found with performance on a task of reading nonsense words.

Reed (1989) presented her subjects with pairs of vowel and pairs of consonant-vowel stimuli with a duration of $250 \mathrm{msec}$ and with pairs of pure tones with a duration of $75 \mathrm{msec}$ (as in the Tallal, 1980, study) and required them to perform a temporal order judgment with ISIs varying from 10 to $400 \mathrm{msec}$. Reed (1989) found that her readingdisabled group was impaired relative to controls as ISIs decreased for pairs of tones and pairs of consonant-vowel syllables. However, the disabled readers were not impaired 
Table 3

Studies Involving Temporal Order Judgments

\begin{tabular}{|c|c|c|c|c|c|c|c|c|}
\hline Study* & $\begin{array}{c}\text { Age } \\
\text { Range } \\
\text { (Years) }\end{array}$ & $N$ & $\begin{array}{l}\text { Selection } \\
\text { Criteria } \uparrow\end{array}$ & Stimuli & $\begin{array}{c}\text { Visual/ } \\
\text { Auditory }\end{array}$ & $\begin{array}{l}\text { Stimulus } \\
\text { Duration }\end{array}$ & $\begin{array}{l}\text { Response } \\
\text { Required }\end{array}$ & $\begin{array}{c}\text { Group } \\
\text { Differences } \\
\text { Found? } \\
\end{array}$ \\
\hline $\begin{array}{l}\text { Brannan \& } \\
\quad \text { Williams (1988) }\end{array}$ & $8-12$ & 15 & A & $\begin{array}{l}\text { 3-letter words } \\
\text { 3-character } \\
\text { symbols }\end{array}$ & $\mathrm{V}$ & $\begin{array}{l}20-70 \mathrm{msec} \\
(\mathrm{SOA})\end{array}$ & $\begin{array}{l}\text { motor (to } \\
\text { place of first } \\
\text { stimulus) }\end{array}$ & $\begin{array}{l}\text { yes } \\
\text { yes }\end{array}$ \\
\hline $\begin{array}{l}\text { Kinsbourne } \\
\text { et al. (1991) }\end{array}$ & Adult & 23 & B & $\begin{array}{l}\text { light flashes } \\
\text { clicks }\end{array}$ & $\begin{array}{l}\mathrm{V} \\
\mathrm{A}\end{array}$ & $\begin{array}{c}20 \mathrm{msec}+ \\
?\end{array}$ & $\begin{array}{c}\text { verbal? } \\
\quad "\end{array}$ & $\begin{array}{l}\text { yes } \\
\text { yes }\end{array}$ \\
\hline $\begin{array}{l}\text { May et al. } \\
\text { (1988) }\end{array}$ & $8: 6-10: 2$ & 7 & $\mathrm{C}$ & $\begin{array}{r}\text { 3-letter } \\
\text { words }\end{array}$ & V & $30-90 \mathrm{msec}$ & $\begin{array}{l}\text { verbal } \\
\text { (to word) } \\
\text { motor } \\
\text { (to position) }\end{array}$ & $\begin{array}{l}\text { yes } \\
\text { yes }\end{array}$ \\
\hline $\begin{array}{l}\text { Muller \& } \\
\quad \text { Bakker (1968) }\end{array}$ & $M=13$ & 20 & $\mathrm{D}$ & $\begin{array}{l}\mathrm{red} / \mathrm{yellow} \\
\text { light flashes }\end{array}$ & $\mathrm{V}$ & $75 \mathrm{msec}$ & verbal & yes \\
\hline Reed (1989) & $7: 9-10: 4$ & 23 & $\mathrm{E}$ & $\begin{array}{l}2 \text { vowels } \\
\text { ba/da } \\
2 \text { tones } \\
2 \text { symbols }\end{array}$ & $\begin{array}{l}\text { A } \\
\text { A } \\
\text { A } \\
\text { V }\end{array}$ & $\begin{array}{c}10-400 \mathrm{msec} \\
" ~ \\
" \\
50-400 \mathrm{msec}\end{array}$ & $\begin{array}{l}\text { motor } \\
\text { (to order) }\end{array}$ & $\begin{array}{l}\text { no } \\
\text { yes } \\
\text { yes } \\
\text { no }\end{array}$ \\
\hline Tallal (1980) & $8-12$ & 20 & $\mathrm{~F}$ & $\begin{array}{l}2 \text { complex } \\
\text { tones }\end{array}$ & A & 8-305 msec & $\begin{array}{l}\text { motor } \\
\text { (to order) }\end{array}$ & yes \\
\hline
\end{tabular}

*Controls used were age-matched normal readers, with the following exceptions: Muller \& Bakker (1968), no controls; Brannan \& Williams (1988) and May et al. (1988), age-matched and adults; Tallal (1980), 8.5-year-olds. $†$ A = At least 1 year below grade level, as measured by Spache Diagnostic Reading Scales; B = Meeting Finucci criteria, based on Gray Oral Reading Test and Wide Range Achievement Test scores; $\mathrm{C}=$ Reading 1 year or more below grade level, as measured by Spache Diagnostic Reading Scales; $D=2$ years behind and 4 years behind population norm based on reading scores; E = Scoring at 22nd percentile or below on reading subtest of Wide Range Achievement Test; F = Formal diagnosis of specific developmental reading delay, reading at least 1 year below chronological age grade placement as measured by the Metropolitan Reading Test.

on tasks involving pairs of vowels. In speech, the stop consonants involve the most rapid spectral changes, on the order of about $40 \mathrm{msec}$, with sounds such as fricatives and nasals involving much less rapid changes, and vowels being the speech sounds requiring the least temporal auditory differentiation (Phillips \& Farmer, 1990). Thus, Tallal's hypothesis predicts that disabled readers should perform as well as normal readers with long-duration vowel pairs, but not with pairs of brief tones or the consonant-vowel syllables whose discrimination depends on rapid temporal processing, precisely the pattern reported by Reed (1989).

Thus, except when the vowel stimuli were used, TOJ studies have invariably shown an impairment for dyslexics using auditory stimuli. However, the picture is not as clear with visual stimuli. Reed (1989) found no significant differences between her reading disabled and normal groups (ca. 8-10 years) for order judgments of two symbols with ISIs of $50-400 \mathrm{msec}$. It should be pointed out that Reed's poor readers were those identified by their schools as reading disabled, and they scored at or below the 22nd percentile on the Wide Range Achievement Test (WRAT) (with a mean percentile score of 10). Thus when percentiles are considered (rather than grade equivalents), a number of these poor readers would not in fact be classified on the WRAT as within the deficient range for singleword decoding. However, this is a criticism that might be aimed at other studies involving dyslexics. Not all studies give the precise criteria according to which reading impairments were defined. (This problem will be discussed more fully in the later section on heterogeneity in dys- lexia.) It is also possible that the ability to make TOJs in the visual modality may be ameliorated in older learningdisabled children, relative to such judgments in the auditory domain, and that this is why Reed found no significant differences with the use of visual stimuli. (See the subsequent discussion on the possible developmental course of temporal processing deficits.) However, such amelioration may not occur for all children. Muller and Bakker (1968; reported in Bakker, 1970) found that 13-year-old learningdisabled children who were approximately 4 years behind in reading scored significantly lower (not much above chance level) than children 2 years behind in reading in a TOJ task involving red and yellow light flashes with a 75msec ISI.

Williams and her colleagues have employed location as a variable in TOJ tasks. Brannan and Williams (1988) presented a three-letter word or three-symbol stimulus for $900 \mathrm{msec}$, with a second word or nonword following at a stimulus onset asynchrony (SOA) of varying lengths. The two stimuli appeared one to the left and one to the right of a fixation point on a screen, and the subject was required to point to the side on which a stimulus appeared first. At every age level (from 8 to 12 years), the poor readers required an SOA of some $20 \mathrm{msec}$ longer than the controls. The results, especially those of the task with symbols, were highly correlated with reading level. It should be noted, however, that these correlations were based on all groups combined. It would be more compelling to show that correlations within groups were significant. May, Williams, and Dunlap (1988) required good and poor read- 
ers to report which of two adjacent words (either side by side or one above the other) with varying SOAs appeared first, and also which position appeared first (no identification required). To identify the word, poor readers required an SOA of approximately $83 \mathrm{msec}$ (SOA was $45 \mathrm{msec}$ for controls). To judge the position, poor readers required an SOA of approximately $68 \mathrm{msec}$ and good readers required $52 \mathrm{msec}$. Differences were significant for both position and identification thresholds. No significant hemifield effects were found for either judgment. Thus, even when no identification was required, poor readers needed longer ISIs in order to make a TOJ. It should be noted here that in both the Brannan and Williams (1988) and May et al. (1988) studies, the poor readers were selected on the basis of their being at least 1 year below grade in reading. As noted earlier with respect to other studies, this would not necessarily meet the criteria for classification as dyslexic. Thus it is interesting to compare the results in these two studies with those, for instance, of Reed (1989). Given the heterogeneity of reading-disabled children, it may well be that studies such as those of Reed (1989) simply did not happen to include enough children with a temporal processing deficit to affect group performance on the visual task significantly. When considering this possibility, however, we should bear in mind Reed's findings for auditory temporal processing tasks. (The possible correlation between auditory and visual temporal processing deficits will be discussed further later in this review.)

In adult dyslexics, Kinsbourne, Rufo, Gamzu, Palmer, and Berliner (1991) found their subjects to be impaired relative to controls on TOJs in both the visual and auditory modalities (for light flashes or clicks). Furthermore, performances on the tests in both modalities were strongly correlated with performance on a rapid automatized naming task, as well as with reading and spelling scores. The visual and auditory TOJ tasks involved presentation of stimuli one to each visual hemifield or one to each ear, and thus problems with cross-hemispheric transfer of information might be invoked to explain the poorer performance of dyslexics. The results of May et al. (1988), however, argue against this possibility.

In short, there is compelling evidence in groups of dyslexics for a deficit in TOJs in the auditory domain, and conflicting evidence for such a deficit in the visual domain. Results of studies would suggest, however, that some younger poor readers, as well as older, more severely disabled readers, may manifest a TOJ deficit in visual tasks as well. However, as noted above, the hypothesis that disabled readers with a TOJ deficit necessarily show a deficit in stimulus individuation tasks has rarely been tested. Similarly, it remains to be determined whether poor readers who show deficits in the more complex task of sequence matching, as outlined below, also show deficits in TOJ tasks.

Discrimination of stimulus sequences. Extensions of the basic TOJ task usually involve discrimination of stimulus sequences composed of multiple (more than two) el- ements. That is, pairs of stimulus sequences are presented, and the subject's task is to make a same-different judgment for each pair. As in previous processing tasks, stimuli can differ along several dimensions. Sequences may vary along the amodal dimensions of duration and location. Thus either light flashes or identical-frequency tones (or even tactile stimuli) can be presented in sequences of long and short stimuli, or of same-length stimuli with varying intervals. Similarly, sequences of identical stimuli, particularly visual or tactile, can be presented in various locations, with either the locations themselves varying, or the order of locations varying. The former (duration) tasks enable one to avoid the spatial element, but necessitate the registration of time intervals, and thus the perception of rhythm.

The issue of identity is avoided in tasks that employ either location or duration variables, although it could be argued that subjects may in fact code stimuli or intervals of different lengths as "long" or "short," and thus confer identities in the latter case. Some researchers using sequencematching tasks do introduce modal-specific variables such as frequency or form and thus require subjects to match on the basis of the order of the identities of the stimuli presented. A major difference between sequence-matching tasks and the TOJ tasks previously described is the addition of a memory requirement. All matching of sequence tasks place substantial demands on memory, because the first sequence must be remembered if the second is to be compared with it.

A number of studies have been conducted in which the performance of dyslexic children has been measured on sequence-matching tasks. Such studies are presented in Table 4. In many of these studies, dyslexic children as a group have been found to be impaired in comparison with controls. Zurif and Carson (1970) found dyslexics to be impaired on both auditory and visual tasks, involving sequences of 5-7 beats (the Seashore Measures of Musical Talents rhythm subtest) or light flashes with long ( $1-\mathrm{sec})$ and short $(500-\mathrm{msec})$ intervals. The dyslexics were also impaired on cross-modal matching tasks (matching dot patterns to click patterns), and results were correlated with reading skill. Impaired performance in comparison with that of controls on the Seashore Rhythm Test was also found for reading-disabled children (and learning-disabled children) in Grades 1-3 by McGivern, Berka, Languis, and Chapman (1991). Bryden (1972) found his poor readers to be worse than controls on several auditory and cross-modal sequence-matching tasks (using tones, light flashes, or black dots on white cards). Performance was correlated with reading ability. Bryden surmised that the deficit was one of verbal coding rather than temporal rhythm perception per se. It should be noted that his subjects were only about 1.5 years behind in reading on the average, as tested on the Gates-MacGinitie reading tests and were from regular classrooms. In addition, stimuli were presented relatively slowly, with a stimulus duration of $250 \mathrm{msec}$ and ISIs of approximately $500-750 \mathrm{msec}$. Slow presentation was also used by Bakker (1967) when he found that his 
more severely disabled readers ( 4 years behind) were worse than his less severely disabled readers ( 2 years behind) on a task requiring reproduction of the order of presentation of letters and meaningful figures, but not on tasks involving meaningless figures. (It should be noted that, as in sequence-matching tasks, there is also a memory load when a single sequence has to be reproduced; in addition, a more complex motor component has been added.) On a task in which digits were used, the severely disabled readers made more errors than did the less severely disabled readers, but the difference was not statistically significant $(p<.10)$. Bakker (1967) did not advance an explanation for this result, other than to speculate that the task might have been too easy. Each stimulus in the set of four was presented for $2 \mathrm{sec}$, with an ISI of $4 \mathrm{sec}$. Again, the presentation in these tasks might have been too slow to permit the identification of any temporal processing deficit that might have been present, and the tasks might only have measured a phonemic or verbal coding deficit, or perhaps a memory deficit.

Finally, Farmer and Bryson (1989) assessed the ability of dyslexics to reproduce visual patterns of letters, presented at various rates either sequentially or simultaneously, relative to both age-matched and reading-level-matched controls. When four letters were briefly presented simultaneously at various locations in a $4 \times 4$ matrix, dyslexics were as able to reproduce the location of the letters as were their age-matched controls. When the letters were presented sequentially (at a rate of $100-400 \mathrm{msec}$ per letter), the dyslexics' performance was significantly worse than that of these controls. When correct reproduction of both location and identity were considered, the dyslexics' performance was even worse, relative to that of the agematched controls, particularly at the slowest rate of presentation. At this rate, analysis of the errors showed that visual coding was no longer primarily being used by the dyslexics (presumably because time permitted the attempt at using phonemic coding). The results of these experiments were taken as evidence of a rapid sequential visual processing deficit in dyslexics, in addition to the phonemic deficit (which was apparent at the slowest rates of presentation).

A few studies requiring matching or recall of stimuli have suggested that dyslexics perform at the same level as normal readers do when nonverbal stimuli are employed, but that they are impaired when verbal stimuli are used. Such results have generally been taken as evidence that

Table 4

Studies Involving Discrimination of Stimulus Sequences

\begin{tabular}{|c|c|c|c|c|c|c|c|c|}
\hline Study* & $\begin{array}{l}\text { Age } \\
\text { Range } \\
\text { (Years) }\end{array}$ & $N$ & $\begin{array}{l}\text { Selection } \\
\text { Criteria } †\end{array}$ & Stimuli & $\begin{array}{c}\text { Visual/ } \\
\text { Auditory }\end{array}$ & $\begin{array}{l}\text { Stimulus } \\
\text { Duration }\end{array}$ & $\begin{array}{l}\text { Response } \\
\text { Required }\end{array}$ & $\begin{array}{l}\text { Group } \\
\text { Differences } \\
\text { Found? }\end{array}$ \\
\hline Bakker (1967) & $9: 5-15: 2$ & 27 & A & $\begin{array}{l}4 \text { nonsense } \\
\quad \text { figures } \\
4 \text { meaningful } \\
\text { figures } \\
4 \text { letters } \\
4 \text { digits }\end{array}$ & V & $4 \mathrm{sec}$ & $\begin{array}{l}\text { verbal } \\
\text { (for order) }\end{array}$ & $\begin{array}{l}\text { no } \\
\text { yes } \\
\text { yes } \\
\text { no }\end{array}$ \\
\hline Bryden (1972) & $9-10$ & 20 & B & $\begin{array}{l}3-5 \text { tones } \\
3-5 \text { flashes } \\
3-5 \text { dots } \\
\text { Combinations } \\
\quad \text { of above }\end{array}$ & $\begin{array}{c}\text { A } \\
\text { V } \\
\text { V } \\
\text { A/V }\end{array}$ & $\begin{array}{c}500-750 \mathrm{msec} \\
" \\
" \\
"\end{array}$ & verbal (S/D) & $\begin{array}{c}\text { yes } \\
\text { no } \\
\text { no } \\
\text { yes } \\
\text { (3/6 tests) }\end{array}$ \\
\hline $\begin{array}{l}\text { Farmer \& Bryson } \\
\quad(1989)\end{array}$ & $12-18$ & 16 & $\mathrm{C}$ & $\begin{array}{l}4 \text { letters in } \\
\text { matrix }\end{array}$ & V & $\begin{array}{l}\text { Simultaneous } \\
\text { presentation } \\
(200-800 \mathrm{msec})\end{array}$ & $\begin{array}{l}\text { motor } \\
\text { (to location/ } \\
\text { identity) }\end{array}$ & no \\
\hline & & & & & & $\begin{array}{l}\text { Sequential } \\
\text { presentation } \\
(100-400 \mathrm{msec} / \mathrm{letter})\end{array}$ & & yes \\
\hline $\begin{array}{l}\text { Fisher \& } \\
\quad \text { Frankfurter (1977) }\end{array}$ & $M=10: 8$ & 12 & D & $\begin{array}{l}2,4, \text { or } 6 \\
\quad \text { letters in matrix }\end{array}$ & $\mathrm{V}$ & $\begin{array}{l}\text { Simultaneous } \\
\text { presentation } \\
(200 \mathrm{msec})\end{array}$ & $\begin{array}{l}\text { motor (to } \\
\text { location/ } \\
\text { identity) }\end{array}$ & no \\
\hline $\begin{array}{l}\text { McGivern } \\
\text { et al. (1991) }\end{array}$ & $6: 7-12: 2$ & 24 & $\mathrm{E}$ & $\begin{array}{l}\text { Seashore } \\
\text { Rhythm Test }\end{array}$ & A & - & verbal & yes \\
\hline $\begin{array}{l}\text { Zurif \& } \\
\quad \text { Carson (1970) }\end{array}$ & Grade 4 & 14 & $\mathrm{~F}$ & $\begin{array}{l}\text { 5-7 beats } \\
\quad \text { (Seashore MMT) } \\
3-4 \text { light flashes } \\
2-7 \text { clicks/dots }\end{array}$ & $\begin{array}{c}\mathrm{A} \\
\mathrm{V} \\
\mathrm{A} / \mathrm{V}\end{array}$ & $\begin{array}{c}- \\
500-1,000 \mathrm{msec} \\
500-1,000 \mathrm{msec}\end{array}$ & $\begin{array}{c}\text { verbal (S/D) } \\
\qquad " \\
"\end{array}$ & $\begin{array}{l}\text { yes } \\
\text { yes }\end{array}$ \\
\hline
\end{tabular}

Note-Seashore MMT, Measures of Musical Talents. *Age-matched normal readers were used as controls in all studies, with the following exceptions: Bakker (1967), no controls; Farmer \& Bryson (1989) and Fisher \& Frankfurter (1977), age-matched and reading-levelmatched groups. $\quad \uparrow \mathrm{A}=$ Leesvaardigheidstest (standardized reading test); $\mathrm{B}=\mathrm{Based}$ on composite scores derived from Gates-MacGinitie reading tests (about 1.5 years below average); $\mathrm{C}=$ Reading at least 2 years below grade level, measured on Wide Range Achievement Test-Revised; $\mathrm{D}=$ At least 2 years below grade level, based on Gates-MacGinitie Vocabulary Test; $E$ = Reading at least 1 grade level below normal, exhibiting phonetic or written letter/word reversals; $F=$ Average of 2 grade levels below chronological age expectations, based on Gates-MacGinitie Reading Test. 
dyslexics have a purely phonemic or linguistic deficit, rather than a more general sequencing deficit. However, the studies that have used verbal and/or nonverbal stimuli have not been designed so that they might allow the assessment of the independent roles of verbal coding and a temporal/ sequential processing deficit. Some have employed simultaneous rather than sequential presentation, and others have employed slow sequential presentation of stimuli, which allows verbal coding of the information and does $r . t$ permit an assessment of rapid temporal processing ability. For instance, in the study by Katz et al. (1981), each stimulus set (five nonsense drawings or five common object drawings) was presented simultaneously for $4 \mathrm{sec}$. The dyslexics were impaired only when common object drawings (that were verbally codable) were presented. Vellutino, Steger, Kaman, and De Setto (1975) found no group differences when 3-5 Hebrew letters were presented to non-Hebrew reading good and poor readers, but again simultaneous presentation (for $3-5 \mathrm{sec}$ ) was used. Generally, when group differences have been found with verbal but not with nonverbal stimuli when the stimuli are presented sequentially, very slow presentation rates have been used. Holmes and McKeever (1979) presented 20 words or faces, after which subjects were asked to put the stimuli in the order in which they had been presented. Dyslexics did not recall the order of the words as well as did their age-matched controls. Both groups recalled the order of the faces equally (which was not very well). The stimuli were presented at the rate of one per $3 \mathrm{sec}$, far too slow for any temporal processing deficit to become apparent. Further, given the number of stimuli, as well as the slow rate of presentation, a heavy memory component was obviously involved.

In the study by Katz et al. (1983), poor readers were found to be impaired versus age-matched controls on tasks in which either the temporal or the spatial order of letters had to be recalled. Katz et al. (1983) concluded that the dyslexics' deficit was linguistic in nature. Again, however, the slow presentation of the stimuli (approximately one per second) precluded any assessment of a temporal processing deficit for rapidly presented material. Fisher and Frankfurter (1977) found that their dyslexic subjects were superior or equal to reading-matched and age-matched controls at reproducing letter sets simultaneously presented in a $4 \times 4$ matrix for $200 \mathrm{msec}$, particularly when stimulus sets were followed by a mask. Again, however, the stimuli were not presented sequentially, so no conclusions can be drawn about a possible temporal processing deficit (or absence thereof) from this study.

The conclusions drawn in studies such as that of Vellutino et al. (1975) have been questioned by Gross and Rothenberg (1979), who cautioned against the premature and possibly erroneous rejection of a hypothesis, particularly when the hypothesis has been tested on such a heterogeneous group as dyslexics. Existing sequence-matching studies, although they may provide evidence for a phonemic deficit, generally do not enable us to determine whether a sequential or a temporal processing deficit (that may underlie the phonemic deficit) is also present. For instance,
Brady, Shankweiler, and Mann (1983) concluded that, compared with controls, poor readers were impaired in the auditory perception of speech sounds presented in noise, but not in the perception of nonspeech sounds. However, the nonspeech sounds used were environmental sounds such as the music of a piano, knocking on a door, thunder, the ringing of church bells, and so forth, which were apparently not equated with the speech sounds in acoustic properties. When environmental sounds matched to speech sounds in acoustic features are used, dyslexics may be found to be impaired on nonverbal discrimination also. Breedin, Martin, and Jerger (1989), for example, tested a learning-disabled child for discrimination and identification of both speech and nonspeech sounds (in noise), and found him to be impaired with speech sounds only. However, when he was retested with nonspeech sounds that were acoustically matched to speech sounds, he was found to be impaired (relative to a younger control group) on nonspeech sounds in noise also.

One exception to the general trend of presenting stimuli slowly in sequence-matching tasks is the study by Farmer and Bryson (1989), in which dyslexics were no worse than age-matched controls when stimuli (four letters) were presented simultaneously, but were less able to reproduce the correct location/identity of the letters when they were presented rapidly in sequence. It should be emphasized here that the simultaneously presented stimuli were also exposed for relatively short durations, but it was only with sequential presentation of the stimuli that dyslexics were impaired. It could be argued that the dyslexics did not perform as well as the controls with sequential presentation of the letters because they had a problem in directing attention to each successive letter as it appeared. However, a third experiment conducted in this study required subjects to reproduce the order of four letters sequentially presented in the same location, and the dyslexics were more impaired than their age-matched controls on this task also. In this third task, attention would already be concentrated on the location of the successive letters, and thus the argument for a deficit in automatically summoning attention to the location of any new stimulus with an abrupt onset cannot be supported.

As can be seen from the preceding discussion (and from Table 4), many but not all studies have yielded differences between dyslexics and controls on tasks requiring discrimination of stimulus sequences. However, the following trends have emerged: (1) Studies in which group differences have been found for verbally codable but not verbally noncodable stimuli have used either simultaneous presentation of sets or very slow sequential presentation; (2) in such studies, the performance of the controls for noncodable stimuli has generally been impaired relative to their performance for codable stimuli, whereas the dyslexics' performance has generally been similar for the two types of stimuli; and (3) even in those studies where group differences have been found for both verbal and nonverbal stimuli, the presentation rate has almost always been relatively slow. Therefore, although most of the studies reviewed in this section have shown group differences, 
the methods used are not directly relevant to the evaluation of rapid temporal processing deficits.

When the results of studies involving sequence matching or discrimination with rapid presentation are considered, however, it is important to keep in mind the different and more complex processes involved in such tasks. Although it is entirely possible that a temporal processing deficit might indeed lead to poor performance on these tasks, it is also possible that a breakdown in some other process (such as attention or memory) could also contribute to impaired performance. Thus it is important that any study investigating a temporal processing deficit using such tasks control for these other variables.

\section{Summary of Temporal Processing Review}

Under the general rubric of "sequential processing," we have discussed four separate components of temporal information processing: detection or identification of a single stimulus; stimulus individuation, or minimum separation threshold determination (including temporal integration of form); TOJs for two stimuli (including same/different discriminations); and discrimination of sequences. Researchers who have investigated the temporal/sequential processing abilities of dyslexics and normal readers have used different types of tasks (some involving verbally codable, and some nonverbal, stimuli), and, as we have shown, dyslexics are impaired on a number of these tasks involving one or another component of temporal or sequential processing. However, as can be seen from Table 1, dyslexics usually have not been found to be impaired on tasks requiring detection or identification of a single, briefly presented stimulus. On stimulus individuation tasks, however, dyslexics have been shown to be impaired relative to controls on both auditory and visual tasks involving nonlinguistic stimuli such as clicks, tones, lines, and gratings. On TOJ tasks, the preponderance of evidence is for a deficit for dyslexics on auditory and visual tasks, with some evidence that older dyslexics may be less impaired on visual than on auditory tasks. For these TOJ tasks, the stimuli used were a mix of linguistic and nonlinguistic, such as tones, syllables, words, symbols, and light flashes. Finally, on sequence-matching tasks, most of the studies reviewed have found deficits for dyslexics on both auditory and visual tasks. Many of the studies used nonlinguistic stimuli such as tones, dots, symbols, and flashes. Because of the methodological variables of slow sequential or simultaneous presentation of stimuli in some cases, the evidence is not so easily attributable to a temporal processing deficit in most cases. However, because so many of the studies in which dyslexics were found to be impaired involved tasks using nonlinguistic stimuli, the hypothesis that dyslexics' problems are based purely on phonemic, or linguistic, deficits does not seem adequate.

Any single study we have reviewed may be subject to one particular criticism or another. However, the weight of the evidence leads to the conclusion that temporal processing difficulties occur frequently in dyslexics and may be an important consideration for the investigation of the underlying causes of dyslexia.
A caveat is in order here. Although reading-disabled groups may be impaired relative to controls in temporal processing tasks, it is not the case that all of the dyslexics studied are impaired on those tasks. Indeed, when a breakdown of the data has been reported, it is apparent that group results may often be attributable to a proportion (sometimes a minority) of subjects who may be severely impaired on temporal processing tasks. For instance, in the Tallal (1980) study TOJ task, $55 \%$ of the reading-disabled children performed within normal limits, with the other $45 \%$ performing below the level of the worst control. Results such as these serve to underline the heterogeneity of presentations and, undoubtedly, etiologies in readingdisabled children.

Nonetheless, the accumulation of evidence from a diversity of methodologies for a temporal processing deficit for nonspeech sounds, as well as for visual stimuli, lends credence to the hypothesis that some dyslexics may have a general temporal processing deficit. Indeed, there is some evidence that a general temporal processing deficit may extend to the province of motor movements also. Some of this evidence is presented below.

\section{Motor Sequencing Deficits Related to Reading Ability}

It is not our intent in this paper to extensively review the literature regarding deficits in motor sequencing tasks in disabled readers. However, a few of the relevant studies are presented here to provide an indication that difficulties with generating sequential movements have been noted in dyslexics. In the studies that are available, very different tasks have been employed, involving the generation of sequential movements, rather than the processing of presented stimuli. Therefore, these tasks do not readily lend themselves to classification under the component headings used to describe sequential/temporal processing tasks employing visual or auditory stimuli.

First, it should be noted that performance on sequential motor movements has been shown to be related to reading ability. Share et al. (1984) found that interdigital dexterity (particularly when combined with phonological processing skills) was a strong predictor of reading ability. It has been noted that dyslexics have subtle difficulties with sequential motor movements, particularly when interlimb coordination is required (Gladstone, Best, \& Davidson, 1989; Klicpera, Wolff, \& Drake, 1981; Wolff, Cohen, \& Drake, 1984). For instance, Wolff, Michel, Ovrut, and Drake (1990) found that both adolescent and young adult dyslexics performed comparably to controls on tasks involving synchronous finger tapping, but were impaired relative to both normal readers and nondyslexic learningdisabled controls on tasks requiring asynchronous bimanual finger tapping. Wolff et al. (1990) speculated that their findings could reflect a left-hemisphere-based temporal resolution deficit, or impaired interhemispheric communication in dyslexics. Dyslexics are adversely affected by increases in speed requirements in motor tasks (Wolff et al., 1984, 1990). Earlier work by this group (Wolff et al., 1984) revealed a relationship between performance on bimanual 
and asynchronous tapping tasks, but not unimanual tasks, and various reading and rapid naming measures. However, dyslexics may also show deficits on some unimanual motor tasks. Gardiner (1987) found that adult dyslexics performed as well as controls on some unimanual tapping tasks that required reproduction of rhythmical patterns. These dyslexics were significantly impaired, however, when required to reproduce patterns in which another pattern was embedded. Gardiner suggested that the patterns that were difficult for dyslexics to reproduce required concurrent processing at two different levels and that it was the necessity to coordinate two levels of processing that was creating problems for the dyslexics. Supporting evidence for the difficulty of dual processing for dyslexics comes from a study done by Nicolson and Fawcett (1990). These authors compared the performance of adolescent dyslexics with that of age-matched normal readers on a number of motor tasks (balancing and walking on a beam). The motor tasks then had to be repeated concurrently with a second task (either counting backward or a choice reaction task for tones). Performance on the motor tasks performed alone was equivalent for the two groups. However, when both tasks had to be performed concurrently, the dyslexics' performance was significantly impaired. Nicolson and Fawcett suggested that their results indicate a difficulty for dyslexics in automatizing skills.

However, Wolf (1991; Wolf \& Obregon, 1992) has suggested that the underlying link between the motor impairments seen in such studies as those of Nicolson and Fawcett (1990) and Wolff and his colleagues $(1984,1990)$ and the language deficits of dyslexics is a failure in a rapid temporal processing mechanism in these poor readers. This suggestion is supported by the evidence of a correlation in dyslexics between performances on bimanual and asynchronous tapping tasks and tasks involving rapid repetition of syllables and rapid naming of colors and words. The generation of motor movements depends on precise and rapid temporal sequencing, and a disruption in this sequencing process could lead to motor difficulties. Some rapid sequential motor movements may originate in the same area of the language cortex that plays a part in discriminating rapid acoustic stimuli such as stop consonants (Ojemann \& Mateer, 1979). Thus, it is not surprising that impairments in phoneme discrimination might be associated with poor motor sequencing ability. Difficulty with processing incoming information may also play a part, however. Performance in such tasks as those described is probably mediated by monitoring self-generated feedback from all the sensory modalities (visual, kinesthetic, tactile, and auditory) stimulated in production. Of interest is the fact that impairments in the perception and production of temporally ordered motor sequences have been noted in language-impaired children also (Stark, Tallal, \& Mellits, 1985; Tallal, 1985, 1988; Tallal, Stark, \& Mellits, 1985).

It is not our intent to suggest that motor sequencing difficulties play any direct or causal role in reading disabilities. Rather, we present this sample of studies to represent some intriguing findings that appear to show a link in some children between motor sequencing difficulties and reading and to support our contention that further investigation of the possible common denominator(s) should be conducted.

\section{The Generality of Possible Temporal \\ Processing Deficits}

As can be seen from the studies reviewed, evidence suggesting temporal processing deficits in the auditory and visual modalities in some dyslexics has been found on various tasks. It is not yet clear, however, whether a deficit in any aspect of temporal processing might be general (i.e., across modalities) or confined to a specific modality. That is, will individual dyslexics who show symptoms of a temporal processing deficit in the auditory modality necessarily show evidence of a temporal processing deficit in the visual modality also? That question remains to be answered definitively, although there is some preliminary evidence.

Kinsbourne et al. (1991) found adult dyslexics to be impaired for TOJs in both the visual and auditory modalities, although, as was pointed out earlier, interpretation of the results must take into account the method of presentation to separate visual fields or ears. Reed (1989) investigated the performance of dyslexics on a TOJ task but failed to find a deficit in the visual modality. It should be remembered, however, that because of equipment limitations, Reed's minimum ISI was $50 \mathrm{msec}$ and her subjects were in the age range at which Tallal, Stark, Kallman, and Mellits (1981; see below) found that dysphasics no longer exhibited a temporal processing deficit in the visual modality.

Until recently, studies that have looked at temporal processing requirements in both the auditory and visual modalities across a wide range of tasks have been undertaken with language-impaired dysphasic children rather than dyslexics. In developmentally language-impaired children, evidence has been found of a deficit in different modalities when rapid temporal analysis was required (see, e.g., Stark \& Tallal, 1981; Tallal et al., 1985), particularly for younger children. In the latter study, dysphasic children 5-9 years old were impaired on a number of tasks involving association or sequencing of rapidly presented auditory, visual, and cross-modal stimuli. Performance on these tasks was correlated with level of language ability, as was performance on a number of tactile and motor sequencing tasks. (In fact, Tallal et al., 1985, found that a combination of auditory, visual, and tactile perceptual and production tasks correctly classified $98 \%$ of their normal or languageimpaired subjects.) The children at the upper end of this age range were not as impaired on the visual TOJ tasks as they were on the auditory, whereas the younger children (5-6 years) were equally impaired in the two modalities (Tallal et al., 1981). In earlier studies, using visual stimuli of relatively long durations, Tallal and her colleagues had failed to find evidence of a temporal processing deficit in the visual domain. For instance, Tallal and Piercy (1973) found no differences between their developmental dysphasic and normal groups (7-9 years) when they used two 
75-msec light flashes of different shades of green with ISIs of 30-428 msec (see also Tallal, 1978). However, as noted above, younger dysphasics have been found to be impaired on TOJ tasks in both modalities. In addition, dysphasics at the upper end of the age range (7-9 years) in the Tallal et al. (1981) study were found to be impaired on tasks involving remembering the order of stimulus sequences in both the auditory and visual modalities. ${ }^{5}$

The work of Tallal and her colleagues thus provides evidence for a general temporal processing deficit in language-impaired children. The study by Kinsbourne et al. (1991) suggests that temporal processing difficulties in different modalities may co-occur in dyslexics. What is clearly needed are studies with dyslexics that will give definitive answers to questions of generality. For instance, our review supports the claim that dyslexics generally, or one or more subgroups of dyslexics, have a temporal processing deficit for rapidly presented stimuli, but it remains to be demonstrated whether this deficit is general or across the auditory and visual modalities in individual dyslexics. Furthermore, where there is evidence of a temporal processing deficit in one aspect of sequential processing, such as stimulus individuation tasks, it remains to be demonstrated whether there is necessarily also evidence of such a deficit in more complex aspects of sequential processing, such as TOJ or sequence-matching tasks.

One attempt to answer these questions by using nonverbal stimuli has recently been made by Farmer (1993; Farmer \& Klein, 1993). In this study, a number of visual and auditory tasks were administered to adolescent dyslexics and both age-matched and reading-matched controls. The dyslexics were severely reading disabled (reading an average of five grades below expected level), and none showed any evidence of an attention-deficit disorder. The tasks were based on the breakdown of sequential processing into the various components described above, each incorporating a particular type of temporal processing. Results indicated that the dyslexics were significantly impaired in comparison with their age-matched controls on some, but not all, of the auditory and visual tasks. The dyslexics needed a longer ISI than did their age-matched or reading-matched controls to individuate two auditory stimuli, although it should be noted that the possibility of a response bias could not be entirely ruled out (this was the only task on which the dyslexics and reading-matched controls differed). The dyslexics were also less accurate at making TOJs with auditory stimuli (tones) than were their age-matched controls, but they performed as well as the controls when no order judgments were required. When required to make same-different judgments about pairs of four-tone sequences, the dyslexics performed as well as the controls. (Possible explanations for this result are discussed in Farmer, 1993.) Results in the visual modality were less clear-cut. There was no significant difference in performance on the visual TOJ task, although there was a trend for the dyslexics to be less accurate than the agematched controls with the shorter ISIs. (ISIs of 50, 100, and $250 \mathrm{msec}$ were used.) The dyslexics were significantly less accurate than their age-matched controls at making same-different judgments for sequentially presented patterns of light flashes. In contrast to Farmer and Bryson's (1989) subjects, they were also significantly less accurate at making same-different judgments for patterns of light flashes presented simultaneously. The results on these last two tasks were very highly correlated for the dyslexics $(r=.85)$, but not correlated at all for the two control groups, suggesting that the dyslexics were using a similar strategy for the two tasks, whereas this did not seem to be the case for the controls.

Most importantly, perhaps, the dyslexics' performances on most of the tasks were significantly correlated within and across modalities, as well as with performance on phonemic awareness and word and nonword decoding tasks. A full discussion of the results may be found in Farmer (1993), but these findings appear to give some support to Tallal's hypothesis for a general temporal processing deficit implicated in some cases of reading disability.

\section{Caveats and Qualifications}

Are temporal processing deficits attributable to attention-deficit disorder? Critics of the temporal processing deficit hypothesis might suggest that it is not specifically "temporal" processing, but rather attention that is inefficient in individuals whose performance on the rapid sequential tasks was reviewed above. Attention-deficit disorder (ADD) does coexist with reading disability in a substantial proportion of cases (Dykman \& Ackerman, 1991; Felton, Wood, Brown, Campbell, \& Harter, 1987), although it has been shown that this is more often the case with dyseidetic or mixed/unspecific types than with dysphonetics (Felton \& Wood, 1989).

Results from some studies do seem to suggest that an attentional component may be involved in the impairments found in dyslexics. For instance, Gardiner's (1987) finding that dyslexics had difficulty with concurrent processing at two levels suggests a difficulty with allocating attention. Similarly, Nicolson and Fawcett (1990) found that dyslexics were only impaired on motor tasks when another task had to be performed concurrently. These results could also be interpreted as indicating an attentional deficit in dyslexics, although, as noted earlier, other interpretations have been advanced, such as a failure to rapidly acquire automatization of skills (Nicolson \& Fawcett, 1992). However, it should also be noted that one suggested cause of just such a failure is that dyslexics cannot adequately apply attentional resources (Segalowitz, Wagner, \& Menna, 1992).

The most convincing argument against an ADD explanation for temporal processing deficits comes from evidence that reading-disabled children do not necessarily have difficulty in performing tasks that require sustained attention or that may be considered cognitively demanding or boring. Results such as those of Fisher and Frankfurter (1977), in which dyslexics were found to perform as well as controls with rapid simultaneous presentation of stimuli, indicate that these children can attend to such tasks satisfactorily. The results of the study by Farmer and Bryson (1989) also suggest that dyslexics do not perform less well on tasks involving rapid onset of stimuli because 
they have difficulty abruptly reallocating attention. In that study, the dyslexics did as well as the age-matched controls with simultaneous presentation of four letters, but not when the letters were presented sequentially, either in different locations or in the same location. Farmer's findings (1993; Farmer \& Klein, 1993) that dyslexics can perform as well as controls on a task on which sequences of auditory stimuli have to be discriminated (a task that the authors consider to be very boring) would also suggest that it is not a general attention deficit that is causing the difficulties that poor readers have on tasks requiring rapid temporal processing. The results of threshold studies (see, e.g., Lovegrove, Martin, \& Slaghuis, 1986; Slaghuis, Lovegrove, \& Freestun, 1992) in which dyslexics are equivalent to (or sometimes better than) normals with some stimulus parameters and worse with others are also difficult to explain from an attentional deficit perspective.

Clearly, investigating whether reading-disabled children can perform adequately on tasks requiring attention to meaningless stimuli presented continuously over a period of time will give some indication of whether there is an attention deficit. However, it might be argued that it is the transient nature of sequentially presented stimuli to which reading-disabled children have particular difficulty attending. Tasks that involve sequential presentations of stimuli at varying rates will certainly give an indication of whether any transient stimuli are difficult for dyslexics to integrate, or of the speed at which the process breaks down, but such tasks will not fully answer the question. Such tasks have, in fact, already been included in some of the studies reviewed. (See, for instance, Tallal's, 1980, results at various ISIs.)

It could be argued that evidence showing that individuals with no reading disability are impaired on temporal processing tasks would suggest that a temporal processing deficit is not sufficient to cause a reading disorder. Just such evidence was found in a study by Ludlow, Cudahy, Bassich, and Brown (1983), in which a group of hyperactive children with normal reading ability was found to be impaired on an auditory TOJ task, although they were unimpaired on an auditory gap detection task. It should be noted that when reaction time and accuracy are considered jointly, all three groups of subjects in Ludlow et al.'s study who were classified as hyperactive (hyperactive, hyperactive plus language impairment, and hyperactive plus reading impairment) performed worse than controls on a vigilance task of the sort often used to assess ADD. In contrast, a group of learning-impaired children without hyperactivity performed normally on this task. Furthermore, the learning-impaired children were impaired on both the gap detection and temporal order tasks, whereas the three hyperactive groups were impaired only on the temporal order task. This set of findings is consistent with the claim for a general auditory temporal processing deficit in some language-impaired and dyslexic children ${ }^{6}$ as long as several ad hoc assumptions are accepted: (1) To explain the absence of a gap detection deficit in the dyslexic and languageimpaired children who were also hyperactive, it must be assumed that when hyperactivity and language or reading impairment are comorbid, factors unrelated to a basic temporal processing deficit may underlie both impairments; and (2) the finding that the two temporal processing tasks (gap detection and TOJ) appear to dissociate in the three hyperactive groups might be explained by assuming that TOJs are more difficult than gap detection for hyperactive children. Watson (1992), for example, suggested that children with attention difficulties may perform poorly on some tasks requiring rapid temporal processing because of their inability to attend to task requirements, rather than a perceptual difficulty per se. Therefore it would be reasonable to expect to see some subjects with no reading disability who are impaired on some temporal processing tasks because of attention difficulties. Watson assessed both reading-disabled and math-disabled college students on auditory temporal processing tasks and found only the reading-disabled group to be impaired relative to controls when the mean standard score on five temporal tasks was calculated, suggesting that a temporal processing deficit is indeed specifically related to reading problems, rather than to general learning or attentional problems. Further, in the study by Felton et al. (1987), it was clear that the effects of ADD were apparent on a separate group of tests from those tests affected by the presence of a reading disorder. In particular, rapid automatized naming was affected by the presence of a reading disability, but not by ADD. Given the reported relationship between rapid naming and a phonemic deficit, if one further extends the argument to incorporate the temporal processing deficit as an underlying contribution to the phonemic deficit, the differentiation in these tasks is significant.

What the studies reviewed do tell us, however, is that with simultaneous presentation of stimuli, or with less rapid sequential presentation of stimuli, dyslexics can perform at the same level as normal readers do. This evidence argues against invoking such explanations as an attention deficit or a difficulty with processing a large number of stimuli per se, when dyslexics are shown to be impaired on tasks involving the rapid sequential presentation of stimuli.

Heterogeneity of the reading-disabled population. The question of the heterogeneity of reading disabilities was touched on earlier in this paper. It is clear from the work on subtypes cited earlier that there are many different profiles for children who have difficulty with reading. Because of differing experiences with language development and exposure to reading and/or phonemic awareness training, there could be quite different phenotypical representations of the same underlying genotypes. Conversely, reading-disabled children who superficially appear to have similar profiles may have quite different underlying etiologies that happen to have manifested themselves in similar ways. It is clear, just from the studies cited in the earlier sections of this paper, that the subjects examined and described variously as reading disabled or learning disabled may have quite different types of reading disability, both within and among studies. A perusal of Tables $1-4$ will indicate the degree to which criteria for sub- 
ject selection vary across studies. Some investigators have selected a criterion for reading disability of 1 year below expected reading level, whereas others have selected 2 or more years behind in reading. Some investigators have relied on teacher selection or previous classification of the children as reading impaired, whereas others have measured reading level in each of their subjects. Even in cases in which reading level has been measured, many different reading tests have been employed across studies. Some investigators have used tests of reading comprehension, some have used tests of single-word or passage decoding, and some have used a combination of tests. Some investigators have based selection on reading results only, whereas others have looked at results on spelling and/or arithmetic tests in addition to reading level.

Even when scrupulous attention is paid to subject selection, and subjects are chosen on the basis, perhaps, of decoding skills measured by standardized tests, a number of different causes might contribute to an impaired reading level, and thus to differential performance on various tasks even within a reading-disabled group. As was seen in such studies as that of DiLollo et al. (1983) and Tallal (1984), some reading-disabled subjects may have no difficulty on tasks involving rapid presentation of stimuli, whereas others may be severely impaired. We have found similar results (Farmer, 1993; Farmer \& Klein, 1993): some adolescent dyslexics had no difficulty with the tasks in either one or both modalities, whereas other dyslexics had great difficulty. Some of these findings may be due to a developmental amelioration of the deficit (see the discussion in the following section). It is almost certainly the case that even if a temporal processing deficit is causally related to reading disability in some children, it will not necessarily be related in others. Indeed, Tallal and Stark (1982) found that 7- to 9-year-old reading-disabled children selected on the basis of having no evidence of a receptive or expressive language deficit did not differ from a group of controls on temporal perceptual tasks or on a test of phonics skills. (The language-intact reading-disabled children were impaired, however, on tasks involving serial memory, concept generalization, segmentation into syllables, and visual scanning.) It thus seems unlikely that these children's reading disability was attributable to a basic difficulty in processing rapidly presented stimuli. Perhaps a temporal processing deficit would be found primarily in reading-disabled children who show concomitant language deficits. Stanovich (1986a) has noted that reading-disabled children have many language problems. However, even within this large group of dyslexics, it seems unlikely that a single underlying cause will be found for the reading difficulties, given the difficulty of classifying such children into the various subtypes. Stanovich (1986a) has further suggested that even if early reading failure can be attributed to a specific cause, learning (and failing) experiences and their repercussions may result in a more generalized cognitive deficit in older readingdisabled children.

Such heterogeneity in the reading-disabled population means that research into underlying causes will be fraught with difficulties and characterized by potential contradictions, especially if the heterogeniety is not acknowledged. It may be that in addition to the type of group studies already undertaken, single case studies of reading-disabled children with and without language deficits, or with and without temporal processing deficits, will add to our knowledge about the various types of reading disabilities and possible underlying causes. However, individual case studies give no information about the frequency with which different subtypes occur in the population. Unfortunately, another source of complication in investigations of temporal processing deficits as a possible cause of some reading disabilities may be the developmental course of such deficits.

The developmental course of visual and auditory temporal processing deficits. The developmental course of a general temporal processing deficit might appear to be resolved earlier in the visual than in the auditory modality, because of the different temporal demands in the two systems. The ramifications of a temporal processing deficit might also be more severe in the auditory modality, particularly if amelioration is occurring developmentally earlier in the visual system. The establishment of the existence of a relationship between auditory and visual temporal processing deficits may be complicated, however, by the different developmental courses apparent for such deficits in each modality.

In the literature describing temporal processing studies involving stimulus individuation tasks, there is considerable evidence of a developmental trend, with younger children (under 9 years) needing longer ISIs to separate or detect a gap between two stimuli than older children, both in the auditory domain (Davis \& McCroskey, 1980; Irwin, Ball, Kay, Stillman, \& Rosser, 1985; McCroskey \& Davis, 1976 [reported in McCroskey \& Kidder, 1980]; Morrongiello \& Trehub, 1987) and in the visual (Lovegrove \& Heddle, 1980; see also the visual processing experiments of Arnett \& DiLollo, 1979, and the work with infants by Anthony, Zeigler, \& Graham, 1987).

As with stimulus individuation tasks, there is also evidence that children's ability to detect changes in duration of ISIs in sequences of auditory stimuli (such as white noise bursts) improves with age. Whereas adults can detect changes of $10 \mathrm{msec}$, children (at $51 / 2$ years) need $15 \mathrm{msec}$ or more, and infants (at 6 months) need $20 \mathrm{msec}$ or more (Morrongiello \& Trehub, 1987). If the ability to detect changes is impaired in dyslexics because of a temporal processing deficit, and if it follows a delayed or deviant developmental course, this could explain their poor performance on this type of sequential processing task.

There is currently some evidence that visual temporal processing deficits such as the visual persistence noted in many dyslexics may be ameliorated in the preadolescent and adolescent years (Badcock \& Lovegrove, 1981; DiLollo et al., 1983). This evidence coincides with that of increased phonemic awareness at this age (Johnston, 1982; Siegel \& Linder, 1984). It should be noted, however, that much of this evidence comes from mixed-age studies, rather than studies with groups of children at different ages, or better 
yet, longitudinal studies. Therefore, the apparent resolution of the deficit may be an artifact of sample selection or of methodology. There is also evidence that visual persistence may continue to be a problem for some dyslexics into adulthood (Winters et al., 1989). Evidence of auditory temporal processing difficulties has also been found in some, but not all, college-age disabled readers (Watson, 1992; see p. 16). If indeed such visual and auditory temporal processing difficulties do exist in many dyslexics but generally resolve during development, and possibly before disabled readers are identified (but not before the difficulties have affected the ability to learn to read), the task of finding evidence of these deficits is daunting (Snowling, 1991). However, mapping the course of such deficits, and in particular mapping individual improvements and abilities, would be essential in order to provide the optimal remediation for dyslexics with this deficit at each stage of their development.

It will be recalled that in some of the temporal processing studies involving language-impaired children, there was evidence for impairment in visual tasks with younger (5-6 years) but not older (7-9 years) dysphasic children (e.g., Stark \& Tallal, 1981; Tallal et al., 1981). Both age groups were impaired on auditory tasks.

It is clear from the work to date, with both dyslexics and language-impaired children, that because of the different time frames involved in rapid processing in the auditory and visual domains, and because of possibly differing developmental courses in the two modalities, investigation of a possible general temporal processing deficit will need to be done very carefully. Definitive evidence for the developmental course of any temporal processing deficit must await results from carefully designed and controlled longitudinal studies investigating both the auditory and visual modalities.

The studies reviewed thus far have investigated the behavioral components of a possible temporal processing deficit in dyslexics. The search for causes contributing to reading disabilities will be complicated by the heterogeneity of disabilities, and also by the possible developmental courses of deficits such as a difficulty with rapid temporal processing.

The picture is still further complicated when one considers possible etiologies of a temporal processing deficit. There is clear evidence for a strong genetic component in the phonological aspects of reading disability, as evidenced by heritability studies (Ho \& Decker, 1988; Olson et al., 1989; Pennington \& Smith, 1988; Scarborough, 1989). In addition, the recent large-scale study of Olson et al. (1994) has indicated that phonological and orthographic skills show equivalent degrees of heritability. There is also evidence that auditory perceptual deficits are more likely in older language-impaired children with a positive family history of language/learning disorders than in those with a negative family history, suggesting a genetic component (Tallal, Townsend, Curtiss, \& Wulfeck, 1991). Environment may also play a part. In an interesting study of children who lived in an apartment housing complex built above a busy expressway, Cohen, Glass, and Singer (1973) found that phonemic discrimination ability was correlated with reading ability and floor level of the home (and thus proximity to traffic noise). These results held even after social class and physiological damage were partialed out. Although there was no assessment of a temporal processing deficit in the children in this study, environmental variables were clearly related to the phonemic discrimination difficulties found. The environmental component may contribute less than the genetic component, however. In addition to the heritability studies, there is support for a genetic component in the brain morphology studies reviewed next. Some of this morphological evidence also provides support for the suggestion of impaired discrimination of phonemic patterns and increased visible persistence that interferes with establishment of well-defined visual patterns.

\section{Dyslexia and Brain Morphology}

Although this is not the place for a review of the physical evidence for a genetic component to dyslexia, some discussion of the physiological and anatomical differences found in dyslexic brains, and their putative relationship to the reading disability, may be in order here. (For a full discussion of brain morphology in dyslexics, see the reviews by Bigler, 1992; Galaburda, 1992; and Hynd \& SemrudClikeman, 1989.)

Although it is generally agreed that a majority of readingdisabled children have a phonological deficit, it is also clear that developmental dyslexia is not a homogeneous disorder. Not only have children with reading disorders been found to have quite different presentations (e.g., Boder, 1971; Doehring et al., 1981), but also, similar phenotypical manifestations may be the result of a variety of conditions. The developmental nature of the disorder also means that children with similar predispositions or brain abnormalities may develop quite different disabilities and compensatory abilities. However, recent morphological studies on the brains of dyslexics have revealed some interesting and fairly consistent data.

Both anatomical and physiological studies of dyslexic brains have shown either a reversal or the absence of the normally observed left-larger-than-right planum temporale asymmetries. Autopsies have revealed that in many dyslexic brains the right planum temporale was larger than expected, and no smaller than the left planum temporale, as is usually seen (Galaburda, 1988; Galaburda, Sherman, Rosen, Aboitiz, \& Geschwind, 1985). Magnetic resonance imaging (MRI) studies have confirmed these findings of unexpected symmetries. In contrast, Hynd, SemrudClikeman, Lorys, Novey, and Eliopulos (1990) found that the left planum temporale region was significantly reduced in the 10 dyslexics they studied, resulting in reversed $(R>L)$ asymmetry. Jernigan, Hesselink, Sowell, and Tallal (1991) also found abnormal asymmetries in 20 language- and reading-impaired children, although their data also indicated that the left posterior perisylvian region, which includes the planum temporale, was reduced 
in size. They also found abnormal asymmetries in the prefrontal region $(\mathrm{R}>\mathrm{L})$ and the parietal region $(\mathrm{L}>\mathrm{R})$. In recent reports of adolescent dyslexics (Larsen, Hoien, Lundberg, \& Odegaard, 1990; Lundberg \& Hoien, 1989), symmetry of the plana temporale, determined by magnetic resonance imaging, was linked to performance on phonological tasks. Duara et al. (1991) did not find any significant differences in planum temporale size between their 21 dyslexics and 29 controls, but they did find that two areas in the posterior part of the brain, including the angular gyrus and the posterior pole, tended to be unusually large on the right side in dyslexics. They also found that the splenium was larger in the dyslexics. However, no such differences in the size of the splenium, or the corpus collosum in general, were found in a study of 19 dyslexic children versus controls by Larsen, Hoien, and Odegaard (1992). These researchers did find, however, that approximately two thirds of their dyslexics had symmetrical plana temporale, rather than the normal $\mathrm{L}>\mathrm{R}$ asymmetry. (Larsen et al., 1990, noted that some $70 \%$ of dyslexics were found to have planum symmetry, whereas such symmetry was noted in only $30 \%$ of the control subjects.)

Thus, differences in hemispheric symmetries of the temporal lobe, particularly the planum temporale, have been found fairly consistently in dyslexic brains. It is believed that during fetal development, testosterone may in some way interfere with the neuronal loss in one hemisphere that would normally lead to the asymmetries typically seen (Galaburda, Corsiglia, Rosen, \& Sherman, 1987). The planum temporale is the site of classic speech areas, so the differences observed in this area might appear to support the hypothesis that the basic deficit in dyslexia is purely linguistic.

Structural deviations are not limited to the auditory areas, however. Evidence has also been found for abnormalities in regions associated with visual processing. Abnormalities in the lateral geniculate nuclei of dyslexic brains were found to be confined to the magnocellular layers, where the neurons were smaller than those in control brains, whereas the parvocellular layers were not significantly different from those of controls (Livingstone, Rosen, Drislane, \& Galaburda, 1991). Because smaller neurons likely mean thinner axons, with resultant slower conduction velocities, Livingstone et al. (1991) concluded that these results were consistent with the visual evoked potential (VEP) findings in dyslexics. VEP responses to slow stimuli were normal, but diminished in dyslexics at low contrast levels when rapid stimuli were presented (cf. the suggestion by Lovegrove et al., 1986, of a transient system deficit in dyslexics). In primates, the magnocellular system is capable of rapid axonal conduction, whereas the parvocellular region, which is not so heavily myelinated, is not. Livingstone et al. (1991) thus hypothesized that their findings provide an explanation for the poor performance of dyslexics on tasks involving rapid visual stimuli, and that fast subdivisions of other cortical systems, such as the auditory system, might be similarly affected in dyslexics. ${ }^{7}$ They suggested that "the neuronal subdivisions involved in fast information processing in each modality ... may share particular molecular entities and might therefore be vulnerable to the same pathogenic factors ... in dyslexics the rapid subdivisons (the magnocellular homologues) of many forebrain systems might be slower than normal" (p. 7946). It should be noted, however, that only 5 dyslexic subjects were studied, so a replication of these results with a larger group is needed.

A more recent study of the same five brains (Galaburda, Menard, \& Rosen, 1994) revealed parallel differences in the auditory sensory system. When compared with seven control brains, the dyslexic brains were found to have more small and fewer large neurons in the left medial geniculate nucleus (MGN). Additionally, the left-hemisphere MGN neurons were smaller than those in the right-hemisphere MGN in the dyslexic brains, which was not the case in the control brains. Galaburda et al. (1994) suggested that this anatomical evidence of abnormalities in large-cell (fastprocessing) neurons in the auditory system in dyslexics supported the hypothesis of difficulty in processing rapid transitions in this modality. Again, however, it should be noted that this evidence comes from only five brains, and there is no evidence that these dyslexics were in fact impaired on temporal processing tasks in life.

Other structural deviations found in the brains of dyslexics include polymicrogyria and focal dysplasias, mainly in the left temporal region (Galaburda, 1988; Tallal \& Curtiss, 1990) and both left and right frontal regions (Hynd \& Semrud-Clikeman, 1989), as well as in the thalamus (Galaburda et al., 1985). It has been suggested that such cytoarchitectonic abnormalities may result from the negative effect of testosterone on fetal brain development (Geschwind, 1984), but such deviations may also result from the effect of viral inflammatory processes or toxic substances on fetal neuronal development (Hynd \& SemrudClikeman, 1989).

However, before we assume that structural differences between the brains of dyslexics and those of normal readers are evidence for an anatomical cause of reading disabilities, we should consider the following alternative: that differences in methods and degrees of reading practice have led to structural differences in the brain. That such structural changes may occur as a result of behavioral training has been demonstrated, for example, by Merzenich, Schreiner, Jenkins, and Wang (1993), who showed that areas of the adult owl monkey's primary auditory cortex were greatly enlarged after training in discriminations at certain sound frequencies. Thus, the possibility must be considered that the differences in brain structures found in the studies cited above may be the result of a reading disability or speech perception problem, rather than the cause of such deficits. However, the suggestion that the amount of reading or experience with speech perception has led to structural brain changes must be considered purely speculative at this time.

Psychophysiological studies have also revealed differences in brain activity between dyslexics and normal readers. Differences found have been interpreted as suggesting an impaired visual magnocellular pathway in dyslexics (Chase \& Jenner, 1993; Lehmkuhle, Garzia, Turner, Hash, 
\& Baro, 1993; Livingstone et al., 1991); an impairment in the ability to adequately recruit attentional resources in dyslexics (Segalowitz et al., 1992); a failure to automatize processes such as phoneme discrimination (Wood, Flowers, Buchsbaum, \& Tallal, 1991); or impaired gating mechanisms in dyslexics (Tallal, Sainburg, \& Jernigan, 1991).

It has been suggested that some dysphasics and dyslexics may have impaired thalamic gating mechanisms, which have been described as acting to sharpen the edges of stimuli in the visual and auditory systems (and for the tactile system), thus providing a perceptual "window" for stimulus resolution (Tallal et al., 1991). An impairment in this system would result in poor temporal processing. In turn, poor temporal processing and resolution of stimuli would greatly inhibit the automatization of categorization and recognition skills. If this impairment were present at the stage when infants were learning to perceive and produce speech sounds, the resulting lack of automaticity could have far-reaching effects.

What is currently known about the gating mechanisms in the visual and auditory systems makes the suggestion for their impairment in dyslexics plausible and consistent with the anatomical findings. As noted earlier, there is evidence for an impaired visual magnocellular pathway in dyslexics (Chase \& Jenner, 1993; Lehmkuhle et al., 1993; Livingstone et al., 1991). The magnocellular neurons are involved in motion analysis and in analysis of the relative locations of objects (Berne \& Levy, 1988), and, as noted, are involved in rapid information processing (Livingstone et al., 1991). The magnocellular pathway (like the parvocellular pathway) is routed from the retinal ganglion cells through the optic nerve and optic chiasm to the dorsal lateral geniculate nucleus (LGN) of the thalamus. The auditory neuronal pathway is routed from the cochlea through the cochlear nuclei, the superior olivary nuclei, and the inferior colliculus to the medial geniculate nucleus (MGN) of the thalamus. Within the MGN (specifically within the ventral division of this body) are neurons that respond with both a high degree of frequency selectivity and temporal fidelity (Lennartz \& Weinberger, 1992). From the LGN and MGN, the visual and auditory pathways are routed to the visual and auditory cortex, respectively. At the level of the thalamus, however, both the visual and auditory system axons (and those of the somatosensory system) have connections to the reticular nucleus of the thalamus (RNT), with feedback to the originating nuclei (Berne \& Levy, 1988; Tallal et al., 1991). These "relay" cells involve the neurotransmitter gamma aminobutyric acid (GABA) and are thus presumed to be inhibitory. In the auditory system, afferent inhibition acts to sharpen frequency discriminations, and it has analogous effects in both the visual and somatosensory systems (Berne \& Levy, 1988). Thus feedback from the RNT may be involved in the gating mechanism that ensures fine discriminations, and interference with the system could lead to difficulties in the automaticity of discrimination and categorization of stimuli involving rapid temporal changes.
An alternative mechanism for a temporal processing deficit, based on psychophysiological findings, is an impairment in the ability to adequately recruit attentional resources (Segalowitz et al., 1992), perhaps resulting in a failure to automatize some processes, such as phoneme discrimination (Robin, Tomblin, Kearney, \& Hug, 1989). Automatization of skills is acquired more slowly by dyslexics, with the time increasing exponentially as task complexity increases (Nicolson \& Fawcett, 1992).

If Livingstone et al. (1991) are right in assuming that the fast subdivisions of various cortical systems are adversely affected in dyslexics, this might explain many of the results described in this paper. Such a general deficit could account for the evidence of visual temporal processing deficits in a number of dyslexics, and even possibly for some of the difficulties noted on tasks involving rapid sequential motor movements. A general transientsystem deficit would likely be more salient in the auditory domain, given the faster processing capabilities of the auditory than of the visual system. Thus visual deficits might only become apparent for the majority of dyslexics under particular and perhaps somewhat subtle experimental conditions, as in the studies of Lovegrove and colleagues. If indeed the visual temporal processing deficits found by Lovegrove and his co-workers have a causal effect on reading disability, we may need to develop more refined tasks to investigate this causal effect further. We now turn to an evaluation of how such a causal effect might be manifested in the various modalities.

\section{TEMPORAL PROCESSING DEFICITS AND READING ACQUISITION: EVALUATING THE CAUSAL LINK}

The claim that we have explored above, and for which we believe there is compelling evidence, is that a temporal processing deficit is implicated in many cases of developmental reading disability. The most vocal advocate of this claim is Paula Tallal, who has additionally proposed (Tallal, 1984) that the phonemic deficit noted in so many dyslexics is in fact a symptom of a more general deficit in processing rapid temporal sequences. Tallal's proposal, that a basic perceptual temporal processing deficit underlies (i.e., causes) some of the problems with reading diagnosed as dyslexia, has been viewed by some as highly controversial, and the debate surrounding it has been heated. Our purpose in this section is to consider the plausibility of the proposal, existing evidence relevant to its evaluation, and strategies for more directly testing it.

A temporal processing deficit might manifest itself in the various modalities and affect reading ability to different degrees and in different ways. It may be that a processing deficit for rapidly presented stimuli in the auditory modality has a more pervasive effect on language development and subsequently on reading ability than does a deficit in the visual modality, especially in the early years when phoneme-grapheme correspondences are normally being learned. Normal readers attain rapid and au- 
tomatic learning of these correspondences at this time, and an inability to do so will seriously affect the ability to progress in reading. It may be, however, that a visual temporal processing deficit also contributes to an impaired ability to learn to read. How this might be so will be discussed in the context of recent models of speech perception and reading acquisition.

Models have been proposed for both speech perception (Wickelgren, 1979) and reading (Seidenberg \& McClelland, 1989) that invoke the parallel activation of sets of neural units representing speech sounds or letters presented sequentially. Thus, what is perceived is not a series of individual phonemes or letters, but sets consisting of a phoneme or letter in the context of the phonemes or letters flanking it. Each set activates a particular pattern of excitation in the brain, and temporal order is determined by the particular activation of transitional, context-dependent patterns (Wickelgren, 1979), with the strength of the excitatory patterns being influenced by the frequency with which similar patterns have been perceived in the past. In turn, the strength of activation influences the speed with which future patterns will be correctly identified. This parallel processing of sets of context-dependent stimuli enables the cognitive system to rapidly process incoming phonemic stimuli such as speech, or orthographic stimuli such as material to be read. Although it may seem that such a system would mean a huge increase in the number of possible activational patterns over those required for individual phonemes or letters, the constraints of our phonemic and orthographic systems limit the number of possible combinations (Adams, 1990). This still leaves a relatively large number of patterns that must be activated, however. These must then be learned if understanding (and later, production) of speech and fluent reading are to be attained. For such learning to proceed, it is necessary that the organism be able to discriminate among the various stimuli perceived. Thus, before patterns of stimuli can be discriminated, it is necessary that the subject can easily and automatically recognize the individual units, such as letters. Letters themselves are made up of various individual parts (straight and/or curved lines) juxtaposed in particular patterns. Individual phonemes are also made up of spectral changes in set relationships with each other. Thus, the patterns for letters and phonemes must be learned before these can contribute in a meaningful way to the stimulus sets that must be learned. It will be recalled that dyslexics do more poorly than good readers on tasks that require rapid and automatic naming of letters, for instance. If the units within a stimulus are not clearly and rapidly discriminable, no precise or clearly replicable pattern will be activated. Thus, perception of speech units (or perception of letter units, and the association of the two types) will not be easily and automatically acquired.

\section{How a Phonemic Deficit, and Consequently Dyslexia, Might Arise From an Auditory Temporal Processing Deficit}

As described earlier, there is now considerable evidence that a phonemic deficit is predictive of, and probably causal to, many cases of reading disability. At issue here is whether or not an auditory temporal processing deficit may in some cases underlie the phonemic deficit. We wish to emphasize here that the plausibility of the phonemic deficit hypothesis itself is not being challenged. Reviews such as those by Stanovich (1986a) and Wagner and Torgesen (1987) have evaluated clearly the evidence for phonological problems in many reading-disabled children. In reviewing the evidence of a temporal processing deficit and relating it to the phonemic deficit hypothesis, our intent is only to evaluate the plausibility of Tallal's claim that the phonemic deficit may be the result of an underlying auditory temporal processing deficit. We acknowledge that phonological difficulties in children may not always be attributable to temporal processing difficulties. However, we suggest that auditory temporal processing difficulties are likely to result in phonemic difficulties and may in fact be a major contributor to phonological problems. The following arguments, therefore, are not intended to suggest that the temporal processing deficit hypothesis should replace the phonemic deficit hypothesis. They are presented in support of the proposal that the phonemic deficit itself may in some cases be a resulting symptom of underlying processing difficulties of rapidly presented stimuli. The possible relationships that we are exploring in this section are repesented graphically in the lower pathway of Figure 1. The figure (which is described more fully below), illustrates how temporal processing deficits in either the auditory or the visual modalities might lead to difficulties in reading (the lower and upper pathways in the figure, respectively).

If a temporal processing deficit contributes to a difficulty with perception and discrimination of phonemes, recognition of those phonemes will not occur as easily and automatically as it would in a subject without a temporal processing deficit. Such an impaired recognition would undoubtedly lead to many of the problems described in children with a phonemic deficit who are at risk for reading problems. We therefore need to evaluate the evidence that such a phonemic deficit may be caused by a temporal processing deficit.

A number of researchers have argued that dyslexia is specifically a linguistic problem, based on a phonemic deficit (e.g., Liberman, 1989; Vellutino, 1987). The argument is that phonemes fall into a special class of sounds, are perceived by humans as different from nonspeech sounds, and are classified exclusively by areas in the human brain specialized for speech perception, and that this system is impaired in dyslexia. However, it has also been argued that the "speech" areas do not process speech sounds exclusively, but rather any rapid auditory stimuli, many of which in human experience happen to be speech sounds (Jusczyk, Rosner, Reed, \& Kennedy, 1989; Tallal, 1984). Although the ability to use phonemes as part of a complex communicative system is exclusively human, the ability to discriminate phonemes on the basis of their acoustic properties is not. Many studies have shown that various species can be taught to discriminate phonemes such as the stop consonants and even vowels. These species include pri- 


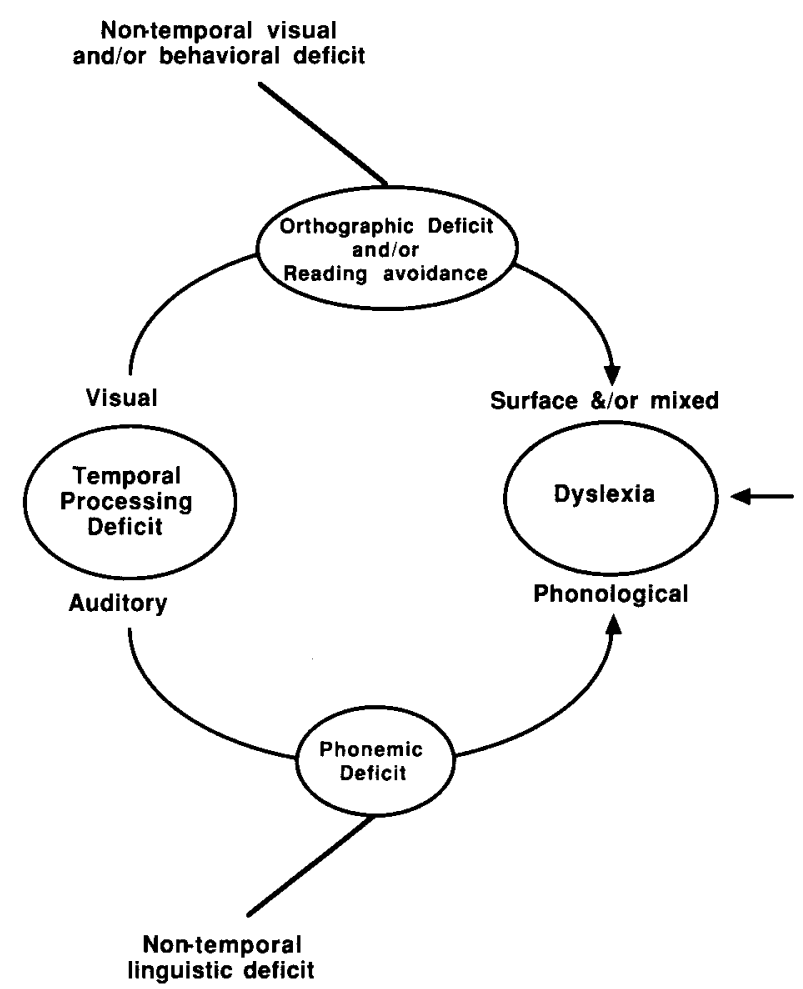

Figure 1. A simplified view of the potential pathways to dyslexia from a temporal processing deficit in either the auditory or the visual modality.

mates such as baboons (Hienz \& Brady, 1988) and birds such as the Japanese quail (Kluender, Kiehl, \& Killeen, 1987). If nonhuman species can learn to categorically perceive phonemes, this argues against a specialized area in the human brain that is devoted purely to perceiving speech sounds and nothing else. For a review and discussion of the evidence for categorical perception of phonemic features in animals, see Kuhl (1986).

Work with infants has shown that even at the early age of 2 months, children categorize both speech and nonspeech sounds (Jusczyk et al., 1989). These categorizations were made when all three sets of stimuli ( $\mathrm{pa} / \mathrm{ba}, \mathrm{du} / \mathrm{tu}$, and tones) had their categorical boundaries in the 20- to $40-$ msec range. Jusczyk et al. concluded that the infants' sensitivity to temporal order differences in the same range for both nonspeech and speech stimuli suggests that specialized speech processing mechanisms to categorize voicing contrasts need not be invoked. (Extensive discussions of these issues can be found in Beck, 1982; Ravizza \& Belmore, 1978; and Thatcher, 1980.) Kuhl (1992) has suggested that infants (and some animals) are innately predisposed to discriminate phonemes - not because they are "prewired" for language per se, but because language has developed to take advantage of preexisting auditory perceptual capabilities. Young infants have the ability to discriminate the phonemes of any language, but lose the ability to distinguish non-native sounds at 6-12 months of age, at the same time as they are learning to categorize their native language phonemes (Kuhl, 1992; Werker, 1989). It appears that experience with prototypes of a phoneme influences the perception of nonprototypical examples of the phoneme such that outliers are categorized with the prototypes (Kuhl, 1992). Although the auditory capacity to discriminate non-native sounds remains (adults can discriminate non-native phonemes when the phonemes are shortened so that they no longer are perceived as language sounds), the ability to discriminate language-like sounds that are not part of the native language is lost in the 1st year of life (Werker, 1989). One might speculate that a disordered or delayed temporal processing system during this critical time would make it difficult for children to discriminate/categorize language sounds and would lead to the sorts of phonemic discrimination and phonemic awareness difficulties that are later seen in language and reading impaired children. Even though the temporal processing deficit may ameliorate to some extent with development, these children may evidence persistent language difficulties (Bernstein \& Stark, 1985; Bishop, 1992). As Stanovich (1986a) has pointed out, "Reading-disabled individuals are characterized by pervasive language problems" (p. 110). Stanovich suggests that the more generalized and complex language impairments seen in dyslexics (such as poor performances on tasks involving semantics, syntax, and metacognitive functioning) may evolve from an initial specific processing deficiency as reading-disabled children experience failure in school and fall further behind as demands increase.

Recent research indicates that the primary auditory cortex is an area implicated in the perception of rapid acoustic events - of durations in the milliseconds to tens of milliseconds (Phillips \& Farmer, 1990). Events of comparable duration include speech sounds such as the stop consonants. It has been suggested that the left hemisphere is primarily involved in rapid temporal processing (Tzeng \& Wang, 1984), and this relative superiority for such processing is reflected in the normally observed right ear advantage (REA) on dichotic listening tasks for verbal stimuli such as stop consonants (Schwartz \& Tallal, 1980). That is, sounds involving rapid acoustic changes are primarily processed by the left hemisphere, and thus sounds directed to the contralateral ear are preferentially processed. Other verbal sounds, such as fricatives, nasals, and vowels produce either a reduced REA or no ear asymmetry (Cutting, 1974; Studdert-Kennedy \& Shankweiler, 1970; Tallal, 1985). There is also evidence of an REA for the processing of temporally complex nonspeech sounds (Divenyi \& Efron, 1979). Thus, it appears to be the left primary auditory cortex that is principally implicated in the processing of rapidly changing acoustic stimuli, perhaps because of its proximity to the "speech" area in the left temporal lobe. It should be noted, relevant to the preceding discussion of differing planum temporale sizes in dyslexics, that the primary auditory cortex is not itself part of the planum temporale in humans; it is situated on Heschl's gyrus, inside the Sylvian fissure. Functionally, the primary auditory cortex receives information from the MGN and 
transmits information to auditory association areas, such as those in the planum temporale, that are involved in higher level processing of the auditory signals.

Those supporting the language-specific phonemic deficit hypothesis have often pointed to the results of studies in which dyslexics have performed as well as controls on tasks involving nonverbal stimuli, but less well on tasks involving verbal stimuli, as evidence in support of the hypothesis. However, as noted earlier, many of these very tasks have involved either simultaneous presentation of stimuli or relatively slow sequential presentation. Thus, the tasks did not allow for an investigation of the possible presence of a temporal processing deficit. Even in some of the studies reviewed, in which differences were found with nonverbal stimuli, with slow presentation it is possible that the differences might have been found because information was being coded verbally, in which case differences might have been attributable to a phonemic deficit in dyslexics that did not allow them to fully utilize mnemonic strategies in these tasks. However, as noted previously, if the phonemic deficit can itself be a symptom of an underlying temporal processing deficit, sequence discrimination tasks that use slow presentation and verbally codable stimuli may well show a deficit for most dyslexics. Thus there is a need for further research using verbally noncodable stimuli with rapid sequential presentation to assess the performance of dyslexics on such tasks. Evidence against the temporal processing deficit hypothesis would be demonstrated if dyslexics were found to perform worse than normal readers on tasks requiring the rapid temporal processing of phonemic stimuli, but equally to normal readers on similar tasks using temporally equated nonverbal stimuli.

The studies reviewed in this paper include, however, a number of recent investigations in which reading-disabled children were found to be impaired on tasks involving rapidly presented nonverbal auditory stimuli. The time frames involved in such presentations were similar to the time frames involved in the spectral changes of many speech components. The temporal processing deficit hypothesis does not deny that many reading-disabled children have a phonemic deficit; it merely suggests that such a deficit may in some cases be subsumed by a more general deficit for processing any rapidly presented auditory stimuli. Perception of spoken language just happens to be particularly vulnerable to such a deficit, because speech is made up of component sounds, some of which (for example, the stop consonants, $/ \mathrm{b} /, / \mathrm{p} /, / \mathrm{d} /, / \mathrm{t} /, / \mathrm{k} /, / \mathrm{g} /$ ) involve rapid spectral changes over a time period of just tens of milliseconds. Tallal proposes that this rapid temporal/sequential processing deficit results in an inability to discriminate many speech sounds. This in turn may lead both to difficulties retrieving phonological codes and to the impaired phonemic awareness and segmentation evidenced by poor readers. Poor speech discrimination may also contribute to the reading problem itself by preventing adequate learning of the phoneme-grapheme correspondences necessary for the normal development of reading skills (Tallal, 1988; Tallal \& Stark, 1982). Poor readers have been shown to be impaired on identification and discrimination tasks for speech sounds such as stop consonants (Godfrey, Syrdal-Lasky, Millay, \& Knox, 1981; Reed, 1989), as well as for nonverbal sounds such as tones (De Weirdt, 1988). In addition to having difficulty in discrimination of rapid speech sounds (Werker \& Tees, 1987), poor readers have also been found to have problems with articulation, particularly with the voicing features of stops (Snowling et al., 1986), and to make many more consonant addition errors in the reading of nonwords (Werker, Bryson, \& Wassenberg, 1989). As noted earlier, the link between early language difficulties and later reading disorder has been firmly established.

The review presented earlier contained a number of studies in which reading-disabled children were shown to have difficulty with discrimination and order judgments involving rapidly presented nonverbal stimuli. Languageimpaired children have also been found to be impaired on such tasks (e.g., Tallal, 1976, 1978). In one such study (Tallal \& Piercy, 1975), dysphasics were impaired on tasks involving either rapidly presented tones or syllables with stop consonants. When the formant transitions of stop consonants were artificially extended to $95 \mathrm{msec}$, dysphasics were not impaired relative to controls for discriminating pairs of stimuli. Moreover, when pairs of different vowel sounds were abbreviated to $43 \mathrm{msec}$ and followed immediately by a longer, different steady-state vowel sound, dysphasics were impaired relative to controls when required to discriminate the pairs based on differences in the first vowel portion. Thus, even when there was no transitional component, dysphasics were unable to discriminate stimuli containing very brief acoustically different portions. In their study with language-impaired children, Tallal et al. (1985) found that the variables that incorporated rapid temporal changes (either nonverbal tones or syllables with stop consonants) were the most predictive of the level of receptive language. Performance on tasks involving longer nonverbal tones or vowel or fricative pairs did not enter the multiple regression equation. Such evidence would certainly seem to indicate that the temporal characteristics of the stimuli are salient with these languageimpaired children, rather than the fact that the stimuli are classified as phonemes. Clearly, studies such as this one need to be conducted with reading-disabled children to discover whether similar results would be found.

It might be argued that temporal processing difficulties are the result of a language difficulty, because children with language impairments have less experience with language and thus less practice at rapidly integrating sensory information in the auditory modality (see, e.g., Watkins, 1990). One obvious way to test this would be to measure the temporal processing abilities of subjects who have little experience with language because of deafness, and this in fact has been done with adults. Poizner and Tallal (1987) investigated the abilities of deaf signers and normally hearing adults on stimulus individuation and TOJ tasks using light flashes and nonverbal symbols. There were no significant differences between the groups' performances. What is needed now is to investigate the temporal process- 
ing abilities of children who have had similarly minimal experience with language. Such studies would help to determine whether the inability to discriminate rapid auditory stimuli predates and affects language development or is dependent on normal language experiences.

Evidence that this inability to discriminate rapidly changing auditory stimuli is general and at a sensory level comes from a study by Stefanatos, Green, and Ratcliff (1989). These investigators noted that previous evoked response studies with language-impaired children have generally failed to yield differences between these children and controls. However, Stefanatos et al. noted that these studies have invariably employed steady-state stimuli such as puretone bursts. Using frequency-modulated tones, Stefanatos et al. (1989) found that expressive developmental dysphasics showed evoked responses similar to those of controls, but that receptive developmental dysphasics showed virtually flat responses. Stefanatos et al. concluded that the latter group's speech perception problems were merely one manifestation of a general difficulty in processing rapid frequency changes at a basic sensory level. There is clearly a need for such tasks as those in the Tallal et al. (1985) and Tallal and Piercy (1975) studies to be carried out with reading-disabled children to see whether the same patterns of results obtain as are found with languageimpaired children. Evoked potential studies such as that done by Stefanatos et al. (1989) would also provide valuable insight into the cognitive processes of readingdisabled children when rapidly presented stimuli are to be discriminated.

\section{How Dyslexia Might Arise From a Visual Temporal Processing Deficit}

A mechanism by which impaired visual temporal processing might directly affect reading acquisition has been proposed by several investigators. DiLollo et al. (1983) suggested that slower processing rates in dyslexics cause an information bottleneck, resulting in incomplete processing and impaired perception. A more specific hypothesis, based on the distinction between transient and sustained channels for visual information processing (Breitmeyer, 1980, 1989; Breitmeyer \& Ganz, 1976), was subsequently elaborated and intensively investigated by Lovegrove, Williams, and their colleagues (see, e.g., Lovegrove et al., 1986; Williams \& LeCluyse, 1990). According to these authors, a transient system deficit may affect reading in two major ways. First, because the transient and sustained systems are mutually inhibitory (Breitmeyer, 1980), reduced transient system efficacy will release the sustained system from inhibition. This will lead to increased persistence (as suggested by DiLollo et al., 1983) that, because of masking by information persisting from the previous fixation, will in turn lead to interference with the information picked up in each fixation during reading. Second, decreased transient activity would delay the processing, or reduce the amount, of parafoveal information available during reading. Good readers integrate such information with foveal information during successive fixations to facilitate fluent reading (Rayner, 1975; Rayner \&
Pollatsek, 1987). The possible relationships that we are exploring in this section are represented graphically in the upper pathway of Figure 1. A visual temporal processing or transient system deficit might directly affect the acquisition of orthographic representations. Alternatively, such a deficit might make reading particularly difficult and unpleasant for the afflicted reader, who would in turn be likely to avoid reading.

A large body of evidence from several paradigms converges on the conclusion that a number of dyslexics may suffer from a transient system deficit. Psychophysical studies aimed at revealing the efficacy of these low-level visual systems have shown, for example, that in comparison with normal readers dyslexics have increased visible persistence with low, but not high, spatial frequencies (Lovegrove et al., 1986), and that the masking from full-field flicker, which is believed to inhibit the transient system, is decreased in dyslexics (Martin \& Lovegrove, 1988). Psychophysiological evidence also points to a transient system deficit (e.g., Lehmkuhle et al., 1993; Livingstone et al., 1991). It should be noted that a transient system deficit could account for many of the temporal processing deficits described in the review section.

In addition, many demonstrations of a dyslexic deficit in visual tasks tapping higher level perceptual function could be interpreted as consistent with a transient system deficit (although, of course, they can be explained in other ways as well). Solman and May (1990), for example, found that poor readers were worse than controls at locating parafoveal patterns, but not when patterns were presented close to the fovea. Mason (1980) found that poor readers were slower and less accurate at identifying a letter in an array of nonletters, but only when the position of the letter was not precued. Mason suggested that lateral masking may be more deleterious for poor readers, who require more time to determine location. Enns, Bryson, and Roes (in press) found evidence to support this suggestion. When required to report the location of a probe letter in an array, dyslexics were impaired relative to age-matched controls regardless of whether the array appeared before, at the same time as, or after the probe letter. Enns et al. (in press) concluded that dyslexics have difficulty in segmenting arrays of letters into spatial/temporal sequences.

Hulme (1988) has challenged the hypothesis that lowlevel visual problems such as the transient system deficit proposed by Lovegrove et al. (1986) could be causal to reading disabilities. Hulme has based his challenge on the evidence that most dyslexics have greater difficulty in reading single words as opposed to words in context, as well as on the evidence that a majority of dyslexics have difficulty in performing phonological coding/phonemic awareness tasks and perform as well as normal readers on visual memory tasks. The latter two lines of evidence have already been addressed in this paper: The phonemic deficit might well be a manifestation of a comorbid temporal processing deficit in the auditory modality, and dyslexics often perform as well as controls on tasks involving simultaneous or slow presentation of visual stimuli. The first argument would at first blush appear to be more persuasive. In- 
deed, like Hulme, many critics of the Breitmeyer/Lovegrove proposal that a visual temporal/transient system deficit may be an underlying cause of dyslexia counter with the ubiquitous finding that dyslexics are more impaired in reading single words than in reading words in context. This argument appears to defeat the causal link suggestion, because when one is reading a single word there is usually no necessity to "clear" the visual buffer via saccadic suppression, and thus no deficit would be expected; in contrast, when one is reading regular connected text, such clearance is repeatedly required. Two points must be emphasized that are usually not acknowledged by these critics. The first is that dyslexics may be impaired in reading single words for two reasons: (1) The visual temporal processing deficit might be one manifestation of a more general deficit, including auditory temporal processing, which we have already shown might produce a reading difficulty via a phonemic deficit; and (2) if reading connected text is difficult because of the transient system deficit, dyslexics will necessarily read less and less successfully, and so will be deficient in comparison with matched controls in precisely the types of knowledge (e.g., orthographicphonological correspondences, pronunciations for irregular words) that depend on reading experience. The second general point about this line of argument is that this comparison is necessarily confounded. With connected text there are not only more opportunities for one fixation to mask the next, but also the possibility for the reader to use context to bypass the decoding stage. Dyslexics, because they are so poor at decoding, may rely on, and thus benefit much more from, context than normal readers do (Snowling, 1987). Both poor readers and less fluent readers may rely on context to a greater degree because their word recognition skills are not as fully automatized or rapid as those of fluent readers (Stanovich, 1980; Stanovich, West, \& Feeman, 1981).

To avoid this confound, it is necessary to keep context constant while varying the possibility of lateral and sequential masking. In one study (Shapiro, Ogden, \& LindBlad, 1990), this was accomplished by comparing the reading of single words out of context that could be seen in one fixation with words long enough to require two or more fixations. Using words appropriate to the reading level of their dyslexic subjects, Shapiro et al. (1990) found that dyslexics (who were at least 2 years below grade level in word recognition) performed as well as age-matched controls when reading short words presented for $100 \mathrm{msec}$ or $300 \mathrm{msec}$, but were worse than controls when reading long words (i.e., words that required a second eye fixation) presented for $300 \mathrm{msec}$. When the long words were presented for $100 \mathrm{msec}$, giving insufficient time for a second fixation, dyslexics and controls did not differ. When given a sufficiently long presentation $(3 \mathrm{sec})$, the dyslexics could read all the words as accurately as controls (though not necessarily as rapidly, but reaction time was not reported). Both groups were found to make one eye fixation to short words, and two to long words. Shapiro et al. (1990) concluded that in dyslexics, information from the second eye fixation was interfering with that from the first. In another study, Hill and Lovegrove (1992) avoided the confound of surrounding print while preserving context by using three conditions to display the same connected discourse: (1) normal text with all the words presented simultaneously; (2) sequential spatial presentation of the same words in the same locations as above, but with only one word displayed at a time (this condition requires the same sequence of saccades, but there would be no masking from information in the periphery); and (3) rapid serial visual presentation (RSVP), whereby each word was presented in the same location, using the same time course as in the sequential condition. In accordance with the predictions following from a transient system deficit, and contrary to the claim that dyslexics are particularly disrupted in reading single words, dyslexics were selectively impaired in the regular text condition - the only condition in which integration of central and peripheral information was required. We wish to make it clear that in this section we are not suggesting that dyslexics will not normally have trouble in reading isolated words. The import of the argument is that when dyslexics are presented with words that they can read, simultaneous visual context or the need for multiple fixations may be especially disruptive for them. Thus, it seems quite reasonable to propose that a low-level transient visual system deficit might be causally related to reading problems in some dyslexics. The longitudinal study by Lovegrove, Slaghuis, Bowling, Nelson and Geeves (1986) suggests that such a transient system deficit may be predictive in prereaders of later reading difficulties.

Hulme (1988) has also pointed out that Boder's (1971) dyseidetic dyslexics (and the mixed dyslexics), who have difficulty recognizing words as visual patterns, are relatively uncommon, whereas Lovegrove has reported visible persistence difficulties in around $75 \%$ of the readingdisabled children (as compared to about $8 \%$ in controls, Slaghuis \& Lovegrove, 1985). Furthermore, Hulme has maintained that Lovegrove's finding (e.g., Martin \& Lovegrove, 1988) that his poor readers were impaired at reading nonsense words is further evidence for a phonological rather than a visual basis to the reading problems. This finding can be easily accommodated by the temporal processing deficit framework as long as a substantial proportion of Lovegrove's dyslexics have a general deficit- that is, one in both the visual and auditory modalities. If that were the case, many of Lovegrove's subjects would also have a phonemic deficit that would likely be the major contributor to their reading disability. Such subjects would be expected to have a nonword reading impairment. The presentation of the reading disorder in such subjects would depend on the relative severity of the temporal processing deficit in each modality. As is illustrated in Figure 1 , a temporal processing deficit might be affecting, in any one individual, either the auditory or the visual pathway, or both. In individuals in whom the auditory pathway is solely, or primarily, affected, the pattern of the reading disorder would presumably present as phonological dys- 
lexia. Subjects who have a visual temporal processing deficit but do not appear to have an auditory one would likely present as Boder's dyseidetic dyslexics. Where the temporal processing deficit was affecting both pathways to a significant degree, the pattern would likely present as mixed. We do not wish to imply here that visual temporal processing difficulties may be, in a large number of cases, the sole cause of reading problems. ${ }^{8}$ Clearly, a large number of dyslexics have a phonemic deficit; for these, a visual processing deficit might add to the problems engendered by phonological difficulties. It might also be the case that the visual processing difficulties seen in some dyslexics versus controls on experimental tasks may not directly affect reading ability at all. However, visual temporal processing difficulties may be diagnostic of a general temporal processing impairment that has its effect on reading ability primarily through the auditory modality. The studies discussed in the generality section suggest that visual and auditory temporal deficits do co-occur, but there are as yet no good data on the rate of co-occurrence. Lovegrove, Pepper, Martin, Mackenzie, and McNicol (1989) found significant correlations among phonological recoding, reading ability, and the magnitude of the visual transient system deficit, thus providing preliminary evidence consistent with this proposal. Such results need to be replicated and explored further to determine what contribution, if any, a visual temporal processing deficit might make to reading disabilities.

\section{Empirical Approaches for Establishing a Causal Link}

Demonstration of an association between deficits is a relatively straightforward empirical affair. To be sure, there are pitfalls, many of which we have discussed in the course of our review. Moreover, strong resistance from an established Zeitgeist can raise the criterion for overcoming these pitfalls and penetrate the literature. We believe that the data reviewed earlier constitute sufficient evidence to warrant further investigation of the link between temporal processing deficits and dyslexia. In the preceding section, we speculated about how temporal processing deficits in either the visual or auditory modality, or both combined, might play a causal role in the emergence of developmental dyslexia. However, even if the association between temporal processing deficits and dyslexia were to be accepted and the plausibility of a causal path from the former to the latter recognized, the hypothesis that temporal processing deficits are the root cause of some cases of dyslexia is far from established. What is needed, in our view, to establish a causal link, is converging evidence from varied methodological domains. Conversely, evidence that young children who continue to manifest a temporal processing deficit in the auditory modality are not found to have a phonemic deficit or to develop reading difficulties would contradict the claims evaluated in this paper. Evidence that some children with a phonemic deficit do not have a temporal processing deficit would be more difficult to interpret, given the possibility of other causes of a phonemic deficit and the possibility of an amelioration of the temporal processing deficit during development. However, findings that a majority of children with phonemic deficits show no evidence of a temporal processing deficit would contradict the hypothesis that a temporal processing deficit is a significant contributor to dyslexia.

Throughout this paper we have referred to the need for further research to clarify some of the issues raised. We do not intend to lay out detailed suggestions for ongoing research proposals, but we will suggest some of the directions that might be followed to provide the kind of converging evidence that could potentially, establish or disconfirm a causal link between temporal processing and dyslexia. Such research might take advantage of a number of techniques, such as statistical or longitudinal studies, genetic studies, cross-cultural studies, physiological or anatomical investigations, and remediation studies. Because of the complexity of a syndrome such as dyslexia, as well as the complicating factors of developmental differences and methodological difficulties in measuring such an elusive deficit, it may be impossible to devise a single conclusive experiment that will provide definitive evidence of a temporal processing deficit's contribution to reading difficulties. Given the numerous diverse areas in which evidence may be collected, however, we feel that if indeed a temporal processing deficit does play a significant part in causing reading disabilities, sufficient converging evidence should be obtainable to provide no reasonable doubt of its culpability. In describing the areas from which such evidence may be obtained, we will use Figure 1 as a guide.

The ideas that we have presented in Figure 1 provide for two pathways from a temporal processing deficit to a reading disability. The lower pathway illustrates how a temporal processing deficit in the auditory modality might lead to a phonemic deficit, which in turn would lead to a reading disability that in all probability would manifest itself as phonological dyslexia. That is, the subject would have difficulty in reading regular and nonwords and constructing spellings that made phonological sense. It will be noted that the model allows for other (nontemporal) causes of a phonemic deficit and thus phonological dyslexia. The upper pathway in Figure 1 illustrates how a visual temporal processing deficit might lead to orthographical problems and/or to an avoidance of reading, and thus to reduced exposure to orthography. Assuming that there is no auditory temporal processing deficit, the subject should be able to learn simple grapheme-phoneme correspondences and thus construct logical spellings and read regular words. However, we might expect the subject to display the type of reading disability that has been classified as surface dyslexia. That is, the subject would have difficulty in reading irregular words, particularly those occurring with low frequency in the written language. Again, note that the model allows for other (nontemporal) visual problems to effect an orthographical deficit, and for environmental/behavioral factors to affect the acquisition of reading skills or to contribute to reading avoidance. When temporal processing is impaired in both the auditory and visual modalities (i.e., when both the lower and upper pathways are operational), we might expect to see subjects with a somewhat different 
(perhaps mixed) pattern of reading difficulties. The arrow to the right of the dyslexia circle in Figure 1 serves as a reminder that other factors might produce neither a phonemic deficit nor an orthographic deficit, but that might contribute to a reading disability.

Sophisticated statistical techniques are available for exploring the different contributions that various skills or abilities may make to the reading process in any group of readers, and what is being tapped during a variety of tasks. Multivariate analyses can be utilized to determine the independent contributions of each measure to the overall variance in performance, as well as their interdependence. Techniques such as factor and path analysis will help to determine what factors are associated with (but not necessarily causal to) a temporal processing deficit. Such techniques can also help to determine what other factors may be associated with, or independent of, the factors of interest. See, for example, the study by Lovegrove et al. (1989) in which visual processing and phonological recoding variables loaded on the same factor, but measures of working memory were not apparently related to either.

Longitudinal studies provide compelling evidence. We therefore strongly urge the investigation of the temporal processing abilities of prereading children as well as their phonemic awareness skills (see, e.g., the study by Lovegrove, Slaghuis, et al., 1986). The development of these skills as the children progress through the early years of school could then be mapped, and their relationship to reading ability measured. If it can be shown that a subgroup of reading-disabled children does have a temporal processing deficit, either in the auditory or the visual modality, or both, then longitudinal studies to map the developmental course of such deficits would contribute greatly to our understanding. As illustrated in Figure 1, the temporal processing deficit makes the very clear prediction that children with an auditory temporal processing deficit would be at risk for developing a phonemic processing deficit and phonological dyslexia. Children with a pure visual temporal processing deficit would be expected to have normal phonemic processing and might later present as surface dyslexics. Such a difficulty might arise because such children have an orthographic deficit directly related to the visual processing deficit, and/or because reading is visually so unpleasant or difficult for them that they avoid it as much as possible, thus reducing their opportunity to be exposed to, and learn, the appearance and pronunciation of irregular words. Longitudinal studies would enable us to determine whether in fact the pattern of reading disabilities predicted by the relative severity of any temporal processing deficits found does occur. In this respect, the types of studies conducted by such investigators as Castles and Coltheart (1993) analyzing individual differences in reading strategies and profiles in developing readers would be invaluable. Levels of temporal processing ability and phonemic discriminability and awareness could be tracked and matched with poor readers' individual profiles to determine whether the patterns of reading disability speculated as being predicted by the temporal processing deficit hypothesis do in fact emerge.
Studies that map the genetic contributions attributable to different aspects of reading, such as phonological and orthographic skills, as well as temporal processing ability, would also tell us much about the possible etiology of deficits and the possible contributions of environment and heritability. The twin study currently under way in Colorado (see Olson et al., 1994) is one such major contribution, and it is of interest to note that Olson et al. plan to include temporal measures in their study. In the light of Olson et al.'s recent findings that orthographical and phonological skills are of approximately equal heritability, family studies that measure the temporal processing skills of parents and siblings of reading-disabled children might also contribute to the advancement of our understanding of the role of temporal processing deficits (although the complicating factor of the possible developmental course of such deficits would have to be kept in mind). We speculate that the hypothesis would suggest that the parent(s) of reading-disabled children with a visual temporal processing deficit who are themselves poor readers (but do not necessarily show a temporal processing deficit) may well display a reading pattern more akin to that of surface dyslexia. The opposite should generally be true for the poorly reading parent(s) of auditory temporal processing deficit children.

Recent advances in psychophysiological techniques hold much promise for contributing to the body of knowledge about reading disabilities. Measures of brain activation in different areas can be correlated with various tasks and compared across groups of children reading at different levels. Different patterns of brain activity might be correlated with different profiles of reading disability, as well as with data from temporal processing tasks, to see what patterns, if any, emerge. It might be speculated, for instance, that auditory and visual temporal processing deficits should be associated with different patterns of brain activity involving auditory and visual neural systems. Longitudinal studies employing noninvasive techniques for measuring brain activity and structures might be used to explore the suggestion that cortical connectivity and anatomy can be altered by reading experience, rather than necessarily being the cause of reading disabilities. That is, children who might be anticipated to be at risk for reading failure (i.e., those with a family history of reading disability) could be followed in order to investigate whether early symmetries/asymmetries in brain structures show any relative changes as reading experience develops. Any such changes (or lack thereof) could be compared with those in a control group of normal readers. It should be noted here that changes in brain structure (a)symmetries (at least in the plana temporale) may be more observable in the presence of a language impairment (that will likely be associated with a reading disability) than in the presence of a reading disability not associated with language impairment. The use of evoked potentials to measure sensory reactions to stimuli can also provide information on early sensory analysis, uncontaminated by subsequent stages of processing. The data obtained from such studies can be correlated with data from temporal processing tasks 
and analyses of reading profiles for the children involved, to see whether any consistent patterns emerge. Of particular interest would be the association, or dissociation, of evoked potential patterns such as those found by Stefanatos et al. (1989), and particular profiles of reading disability.

Finally, remediation studies hold the promise of a wealth of data to help resolve the questions raised. We have already seen that training in phonemic awareness has a positive impact on future reading ability. We have also seen that monkeys can be trained to make temporally finer and finer distinctions between sequentially presented stimuli (Merzenich et al., 1993). We have seen from the studies of Tallal and Piercy (1975) that language-impaired children who cannot discriminate stop consonants can do so when the formant transitions of these stop consonants are artificially extended. It would be most interesting to identify young children who have difficulty with temporal processing (associated with difficulty in speech sound perception), and to train them to make such discriminations by using artificially extended speech sounds that could be gradually reduced in length until they represented the temporal changes normally seen in speech. The rationale for such training is based on the reported categorization of phonemes. If fuzzy phoneme boundaries do indeed lead to phonemic difficulties, the type of training described might lead to more rapid and accurate categorization, and conceivably then to improved phoneme-grapheme correspondence learning. Training with nonspeech sounds in the same time frames as those of speech might be instituted to determine whether such purely temporal (nonlinguistic) training might generalize to the perception of speech sounds and result in increased phonological skills. Phonemic awareness and reading skill could be measured over time, both in these children and in control groups, and correlated with temporal processing ability to see what the relationships are. The question of causality might also be addressed by conducting studies in which phonemic awareness skills per se were trained, and in which the development of these skills over time would be correlated with both reading skill and performance on temporal processing tasks using nonverbal stimuli. The theory predicts that training in phonemic awareness skills should be largely unsuccessful until after any auditory temporal processing deficit has been shown to improve.

Obviously, future research might take a number of directions. We have outlined a few, and we encourage interested readers to apply their own expertise with suitable methods to develop others. In all such studies, care must be taken to exclude possible alternative explanations for the level of performance of reading-disabled children versus their controls. For instance, tasks must be developed that preclude such explanations as poor allocation of attention, or general brain anomalies, for any impaired performance seen in the dyslexics.

\section{CONCLUSION}

In this article, we briefly outlined the empirical support for the widely held hypothesis of a phonemic deficit in many disabled readers. We then reviewed a substantial body of evidence for a more general temporal processing deficit in the auditory domain that has been proposed to underlie the phonemic deficit (Tallal, 1984). The evidence for a temporal processing deficit in the visual domain was also reviewed. All of this evidence was presented in the context of four possible components that we have proposed as aspects of temporal (sequential) processing tasks. In spite of some problems inherent in investigating a temporal processing deficit in dyslexics, it was concluded that the evidence for a temporal processing deficit in dyslexics is sufficiently compelling to warrant further careful investigation of the hypothesis that a temporal processing deficit may be the underlying cause in a significant number of cases of dyslexia. However, the possibility that this deficit is a general one, occurring across modalities, but possibly following different developmental courses within each modality (i.e., ameliorating earlier in one modality), complicates the picture and will make such investigation challenging. Recent anatomical and psychophysiological evidence from studies of dyslexic brains was briefly reviewed, with particular emphasis on converging evidence for a general temporal processing deficit. The proposal that a temporal processing deficit may be causal to some cases of reading disability was described, and the plausibility of causal links from auditory and visual temporal processing deficits to dyslexia was explored. Finally, some empirical strategies for confirmation or disconfirmation of this proposal were briefly outlined.

It is clear that a large body of evidence now shows that there is a temporal processing deficit in a number of dyslexics. However, many questions concerning such a temporal processing deficit remain to be answered, and further research on this problem is clearly needed if we are to determine whether a temporal processing deficit is the underlying cause of reading problems in a subset of dyslexics. In order to answer these questions, future research needs to utilize tasks involving rapid sequential presentation of stimuli in both the auditory and visual modalities. Both verbally codable and noncodable stimuli should be used. Nonlinguistic auditory stimuli should involve presentations in the same time frames as those of speech sounds, particularly the stop consonants. In addition, comparable tasks that clearly do not involve temporal processing should be presented, to determine whether other factors might be contributing to the impaired performance of dyslexics. In this way, hopefully, we can determine the answers to the questions posed in this article. These answers are crucial to our improved understanding of the etiology and developmental course of reading disorders. Such an understanding may better enable us to design selectively appropriate remediation programs for disabled readers of various subtypes at each stage of their individual development.

\section{REFERENCES}

AARON, P. G. (1985). The paradoxical relationship between intelligence and reading disability. Perceptual \& Motor Skills, 61, 1251-1261.

Aaron, P. G., OlsEN, J., \& BaKer, C. (1985). The dyslexic college student: Is he also dysphasic? Cognitive Neuropsychology, 2, 115-147. 
AdAMS, M. J. (1990). Beginning to read: Thinking and learning about print. Cambridge, MA: MIT Press.

ALBert, M. L., \& BEAR, D. (1974). Time to understand: A case study of word deafness with reference to the role of time in auditory comprehension. Brain, 97, 373-384.

Anthony, B. J., Zeigler, B. L., \& Graham, F. K. (1987). Stimulus duration as an age-dependent factor in reflex blinking. Developmental Psychobiology, 20, 285-297.

ARAM, D. M., \& EKELMAN, B. L. (1988). Auditory temporal perception of children with left or right brain lesions. Neuropsychologia, 26, 931-935.

ARNETT, J. L., \& DiLolLo, V. (1979). Visual information processing in relation to age and to reading ability. Journal of Experimental Child Psychology, 27, 143-152.

Auerbach, S. H., Allard, T., Naeser, M., Alexander, M. P., \& AlBERT, M. L. (1982). Pure word deafness. Analysis of a case with bilateral lesions and a defect at the prephonemic level. Brain, 105, 271-300.

BADCOCK, D., \& LOVEGROVE, W. (1981). The effects of contrast, stimulus duration, and spatial frequency on visible persistence in normal and specifically disabled readers. Journal of Experimental Psychology: Human Perception \& Performance, 7, 495-505.

BAKKER, D. J. (1967). Temporal order, meaningfulness, and reading ability. Perceptual \& Motor Skills, 24, 1027-1030.

BAKKER, D. J. (1970). Temporal order perception and reading retardation. In D. J. Bakker \& P. Satz (Eds.), Specific reading disability: Advances in theory and method (pp. 81-96). Rotterdam: Rotterdam University Press.

BAKKER, D. J. (1979). Hemispheric differences and reading strategies: Two dyslexias? Bulletin of the Orton Society, 29, 84-100.

BECK, C. H. M. (1982). Processing of symbolic and nonsymbolic events: A review of comparisons in selected cognitive activities. International Journal of Neuroscience, 17, 93-107.

Beitchman, J. H., \& INGLIs, A. (1991). The continuum of linguistic dysfunction from pervasive developmental disorders to dyslexia. Psychiatric Clinics of North America, 14, 95-111.

Berne, R. M., \& Levy, M. N. (1988). Physiology (2nd ed.). St. Louis, MO: C. V. Mosby.

Bernstein, L. E., \& STARK, R. E. (1985). Speech perception development in language-impaired children: A 4-year follow-up study. Journal of Speech \& Hearing Disorders, 50, 21-30.

BIGLER, E. D. (1992). The neurobiology and neuropsychology of adult learning disorders. Journal of Learning Disabilities, 25, 488-506.

Bishop, D. V. M. (1992). The underlying nature of specific language impairment. Journal of Child Psychology \& Psychiatry, 33, 3-66.

BlackWell, S. L., McInTYre, C. W., \& MurRay, M. E. (1983). Information processed from brief visual displays by learning-disabled boys. Child Development, 54, 927-940.

BoDER, E. (1971). Developmental dyslexia: Prevailing diagnostic concepts and a new diagnostic approach. In H. Myklebust (Ed.), Progress in learning disabilities (Vol. 2, pp. 293-321). New York: Grune \& Stratton.

Bowers, P. G., \& Swanson, L. B. (1991). Naming speed deficits in reading disability: Multiple measures of a singular process. Journal of Experimental Child Psychology, 51, 195-219.

BradLEY, L., \& Bryant, P. E. (1978). Difficulties in auditory organisation as a possible cause of reading backwardness. Nature, 271, 746-747.

Bradley, L., \& Bryant, P. E. (1983). Categorizing sounds and learning to read-A causal connection. Nature, 301, 419-421.

Brady, S., MANN, V., \& SCHMIDT, R. (1987). Errors in short-term memory for good and poor readers. Memory \& Cognition, 15, 444-453.

Brady, S., Shankweiler, D., \& MaNN, V. (1983). Speech perception and memory coding in relation to reading ability. Journal of Experimental Child Psychology, 35, 345-367.

Brannan, J. R., \& Williams, M. C. (1988). Developmental versus sensory deficit effects on perceptual processing in the reading disabled. Perception \& Psychophysics, 44, 437-444.

Breedin, S. D., Martin, R. C., \& Jerger, S. (1989). Distinguishing auditory and speech-specific perceptual deficits. Ear \& Hearing, 10, 311-317

BREITMEYER, B. G. (1980). Unmasking visual masking: A look at the "why" behind the veil of "how." Psychological Review, 87, 52-69.

BREITMEYER, B. G. (1989). A visually based deficit in specific reading disability. Irish Journal of Psychology, 10, 534-541.

BREITMEYER, B. G., \& GANZ, L. (1976). Implications of sustained and transient channels for theories of visual pattern masking, saccadic suppression, and information processing. Psychological Review, 83, 1-36

BRYDEN, M. P. (1972). Auditory-visual and sequential-spatial matching in relation to reading ability. Child Development, 43, 824-832.

BYRne, B., \& SheA, P. (1979). Semantic and phonetic memory codes in beginning readers. Memory \& Cognition, 7, 333-338.

Castles, A., \& Coltheart, M. (1993). Varieties of developmental dyslexia. Cognition, 47, 149-180.

Chase, C., \& JENner, A. R. (1993). Magnocellular visual deficits affect temporal processing of dyslexics. In P. Tallal, A. M. Galaburda, R. R. Llinás, \& C. von Euler (Eds.), Temporal information processing in the nervous system: Special reference to dyslexia and dysphasia (Annals of the New York Academy of Sciences, Vol. 682, pp. 326-329). New York: New York Academy of Sciences.

COHEN, S., Glass, D. C., \& Singer, J. E. (1973). Apartment noise, auditory discrimination, and reading ability in children. Journal of $E x-$ perimental Social Psychology, 9, 407-422.

Cutring, J. E. (1974). Two left-hemisphere mechanisms in speech perception. Perception \& Psychophysics, 16, 601-612.

DAVIS, S. M., \& MCCROSKEY, R. L. (1980). Auditory fusion in children. Child Development, 51, 75-80.

DeNCKLA, M. B., \& RudEL, R. G. (1976). Naming of object-drawings by dyslexic and other learning disabled children. Brain \& Language, 3, $1-15$.

DE WEIRDT, W. (1988). Speech peiception and frequency discrimination in good and poor readers. Applied Psycholinguistics, 9, 163-183.

DiLollo, V., Arnetr, J. L., \& KRUK, R. V. (1982). Age-related changes in rate of visual information processing. Journal of Experimental Psychology: Human Perception \& Performance, 8, 225-237.

Dilollo, V., Hanson, D., \& MCInTYRe, J. S. (1983). Initial stages of visual information processing in dyslexia. Journal of Experimental Psychology: Human Perception \& Performance, 9, 923-935.

DivenYi, P. L. \& EFron, R. (1979). Spectral versus temporal features in dichotic listening. Brain \& Language, 7, 375-386.

Doehring, D. G., Trites, R. L., Patel, P. G., \& Fiedorowicz, C. A. M. (1981). Reading disabilities: The interaction of reading, language, and neuropsychological deficits. New York: Academic Press.

Duara, R., Kushch, A., Gross-Glenn, K., Barker, W. W., Jallad, B. Pascal, S., Loewenstein, D. A., Sheldon, J., Rabin, M., Levin, B., \& LuBs, H. (1991). Neuroanatomic differences between dyslexic and normal readers on magnetic resonance imaging scans. Archives of Neurology, 48, 410-416.

Dykman, R. A., \& ACKerman, P. T. (1991). Attention deficit disorder and specific reading disability: Separate but often overlapping disorders. Journal of Learning Disabilities, 24, 96-103.

EnNs, J., BRYson, S., \& RoEs, C. (in press). Searching for letter identity and location by disabled readers. Canadian Journal of Experimental Psychology.

FARMER, M. E. (1993). A comparison of the sequential processing abilities of dyslexic and normal readers, using visual and auditory tasks. Unpublished doctoral dissertation, Dalhousie University, Halifax, NS, Canada.

FARMER, M. E., \& BRYson, S. E. (1989). Reproduction of simultaneously or sequentially presented letter sets by dyslexic and normal readers. Unpublished manuscript. Dalhousie University, Halifax, NS, Canada.

FARMER, M. E., \& KLEIN, R. (1993). Auditory and visual temporal processing in dyslexic and normal readers. In P. Tallal, A. M. Galaburda, R. R. Llinás, \& C. von Euler (Eds.), Temporal information processing in the nervous system: Special reference to dyslexia and dysphasia (Annals of the New York Academy of'Sciences, Vol. 682, pp. 339-341). New York: New York Academy of Sciences.

FAwCETT, A. J., \& Nicholson, R. I. (1994). Naming speed in children with dyslexia. Journal of Learning Disabilities, 27, 641-646.

FAY, W. H. (1966). Temporal sequence in the perception of speech. The Hague: Mouton.

Felton, R. H., \& Wood, F. B. (1989). Cognitive deficits in reading disability and attention deficit disorder. Journal of Learning Disabilities, 22, 3-13, 22 .

Felton, R. H., Wood, F. B., Brown, I. S., Campbell, S. K., \& Harter, M. R. (1987). Separate verbal memory and naming deficits in attention deficit disorder and reading disability. Brain \& Language, 31, 171-184. FISHER, D. F., \& FrANKFURTER, A. (1977). Normal and disabled readers 
can locate and identify letters: Where's the perceptual deficit? Journal of Reading Behavior, 9, 31-43.

FLETCHER, J. M. (1985). External validation of learning disability typologies. In B. P. Rourke (Ed.), Neuropsychology of learning disabilities: Essentials of subtype analysis (pp. 187-211). New York: Guilford Press.

Foorman, B. R., \& Liberman, D. (1989). Visual and phonological processing of words: A comparison of good and poor readers. Journal of Learning Disabilities, 22, 349-355

FreEBody, P., \& BYRNe, B. (1988). Word-reading strategies in elementary school children: Relations to comprehension, reading time, and phonemic awareness. Reading Research Quarterly, 23, 44 1-453.

FRITH, U. (1986). A developmental framework for developmental dyslexia. Annals of Dyslexia, 36, 69-81.

Galaburda, A. M. (1988). The pathogenesis of childhood dyslexia. In F. Plum (Ed.), Language, communication and the brain (pp. 127-137). New York: Raven Press.

Galaburda, A. M. (1992). Neurology of developmental dyslexia. Current Opinions in Neurology \& Neurosurgery, 5, 71-76.

Galaburda, A. M., Corsiglia, J., Rosen, G. D., \& Sherman, G. F (1987). Planum temporale asymmetry, reappraisal since Geschwind and Levitsky. Neuropsychologia, 25, 853-868.

Galaburda, A. M., Menard, M. T., \& Rosen, G. D. (1994). Evidence for aberrant auditory anatomy in developmental dyslexia. Proceedings of the National Academy of Sciences, 91, 8010-8013.

Galaburda, A. M., Sherman, G. F., Rosen, G. D., Aboitiz, F., \& Geschwind, N. (1985). Developmental dyslexia: Four consecutive patients with cortical anomalies. Annals of Neurology, 18, 222-233

GARDINER, M. F. (1987). General temporal-sequential processing capability required for reading: New evidence from adults with specific reading difficulties. In S. H. Koslow, A. J. Mandell, \& M. F. Schlesinger (Eds.), Perspectives in biological dynamics and theoretical medicine (Annals of the New York Academy of Sciences, Vol. 504, pp. 283-285). New York: New York Academy of Sciences.

Geiger, G., \& LetTVIN, J. Y. (1987). Peripheral vision in persons with dyslexia. New England Journal of Medicine, 316, 1238-1243.

GESCHWIND, N. (1984). Cerebral dominance in biological perspective. Neuropsychologia, 22, 675-683.

GiBBS, D. P., \& COOPER, E. G. (1989). Prevalence of communication disorders in students with learning disabilities. Journal of Learning Disabilities, 22, 60-63.

Gladstone, M., Best, C. T., \& Davidson, R. J. (1989). Anomalous bimanual coordination among dyslexic boys. Developmental Psychol$o g y, 25,236-246$.

Godfrey, J. J., Syrdal-Lasky, A. K., Millay, K. K., \& Knox, C. M (1981). Performance of dyslexic children on speech perception tests Journal of Experimental Child Psychologv, 32, 401-424.

Gordon, H. W. (1984). Dyslexia. In R. E. Tarter \& G. Goldstein (Eds.), Advances in clinical neuropsychology (Vol. 2, pp. 181-205). New York: Plenum

Goswami, U. (1990). A special link between rhyming skill and the use of orthographic analogies by beginning readers. Journal of Child Psychology \& Psychiatry, 31, 301-311.

Gross, K., \& RothenBERG, S. (1979). An examination of methods used to test the visual perceptual deficit hypothesis of dyslexia. Journal of Learning Disabilities, 12, 36-43

Gross-Glen, K., \& RothenberG, S. (1984). Evidence for deficit in interhemispheric transfer of information in dyslexic boys. International Journal of Neuroscience, 24, 23-35.

HAGGERTY, R., \& STAMm, J. S. (1978). Dichotic auditory fusion levels in children with learning disabilities. Neuropsychologia, 16, 349-360.

HienZ, R. D., \& BRADY, J. V. (1988). The acquisition of vowel discriminations by nonhuman primates. Journal of the Acoustical Society of America, 84, 186-194.

HiLl, R., \& Lovegrove, W. [J.] (1992). One word at a time: A solution to the visual deficits in SRDs? In S. F. Wright, R. Groner, \& R. KaufmannHayoz (Eds.), Facets of dyslexia and its remediation (pp. 65-76). Amsterdam: Elsevier, North-Holland.

HirSh, I. J., \& SHERRICK, C. E., JR. (1961). Perceived order in different sense modalities. Journal of Experimental Psychology, 62, 423-432.

Ho, H.-Z., \& DeCKER, S. N. (1988). Cognitive resemblance in readingdisabled twins. Developmental Medicine \& Child Neurology, 30, 99-107.
Holmes, D. R., \& McKeever, W. F. (1979). Material specific serial memory deficit in adolescent dyslexics. Cortex, 15, 51-62.

HoYt, C. S., III (1990). Irlen lenses and reading difficulties. Journal of Learning Disabilities, 23, 624-626.

Hulme, C. (1988). The implausibility of low-level visual deficits as a cause of children's reading difficulties. Cognitive Neuropsychology, 5, 369-374.

HYND, G. W. (1992). Neurological aspects of dyslexia: Comment on the balance model. Journal of Learning Disabilities, 25, 110-112, 123.

Hynd, G. W., \& Semrud-Clikeman, M. (1989). Dyslexia and brain morphology. Psychological Bulletin, 106, 447-482.

Hynd, G. W., Semrud-Clikeman, M., Lorys, A. R., Novey, E. S., \& Eliopulos, D. (1990). Brain morphology in developmental dyslexia and attention deficit disorder/hyperactivity. Archives of Neurology, 47, 919-926.

Irwin, R. J., Ball, A. K. R., Kay, N., Stillman, J. A., \& Rosser, J. (1985). The development of auditory temporal acuity in children. Child Development, 56, 614-620.

Jernigan, T. L., Hesselink, J. R., Sowell, E., \& Tallal, P. (1991) Cerebral structure on magnetic resonance imaging in language- and learning-impaired children. Archives of Neurology, 48, 539-545.

JoHnSON, D. J., \& MYKLEBUST, H. R. (1967). Learning disabilities: Educational principles and practices. New York: Grune \& Stratton.

Johnston, R. S. (1982). Phonological coding in dyslexic readers. British Journal of Psychology, 73, 455-460.

JoRM, A. F. (1983). Specific reading retardation and working memory: A review. British Journal of Psychology, 74, 311-342.

JusCzyK, P. W., Rosner, B. S., ReEd, M. A., \& Kennedy, L. J. (1989). Could temporal order differences underlie 2-month-olds' discrimination of English voicing contrasts? Journal of the Acoustical Society of America, 85, 1741-1749

KAMHI, A. [G.], \& CATTS, H. W. (1986). Toward an understanding of developmental language and reading disorders. Journal of Speech \& Hearing Disorders, 51, 337-347.

Kaмhi, A. G., \& CatTs, H. W. (1989). Reading disabilities: A developmental language perspective. Boston: Little, Brown.

KATZ, R. B. (1986). Phonological deficiencies in children with reading disability: Evidence from an object-naming task. Cognition, 22, 225-257.

Katz, R. B., Healy, A. F., \& Shankweiler, D. (1983). Phonetic coding and order memory in relation to reading proficiency: A comparison of short-term memory for temporal and spatial order information. Applied Psycholinguistics, 4, 229-250.

Katz, R. B., Healy, A. F., \& Shankweiler, D. (1984). On accounting for deficiencies in order memory associated with reading difficulty: A reply to Tallal. Applied Psycholinguistics, 5, 170-174.

KATZ, R. B., \& SHANKWEILER, D. (1985). Repetitive naming and the detection of word retrieval deficits in the beginning reader. Cortex, 21, 617-625.

Katz, R. B., Shankweiler, D., \& Liberman, I. Y. (1981). Memory for item order and phonetic recoding in the beginning reader. Journal of Experimental Child Psychology, 32, 474-484.

Kinsbourne, M., Rufo, D. T., Gamzu, E., Palmer, R. L., \& Berliner, A. K. (1991). Neuropsychological deficits in adults with dyslexia. Developmental Medicine \& Child Neurology, 33, 763-775.

Klein, R., Berry, G., Briand, K., D'Entremont, B., \& Farmer, M (1990). Letter identification declines with increasing retinal eccentricity at the same rate for normal and dyslexic readers. Perception \& Psychophysics, 47, 601-606.

KlicPera, C., WolfF, P. H., \& Drake, C. (1981). Bimanual co-ordination in adolescent boys with reading retardation. Developmental Medicine \& Child Neurology, 23, 617-625.

Kluender, K. R., Kiehl, R. L., \& Killeen, P. R. (1987, September 4). Japanese quail can learn phonetic categories. Science, 237, 1195-1197.

KUHL, P. K. (1986). Theoretical contributions of tests on animals to the special-mechanisms debate in speech. Experimental Biology, 45, 233265

KuHL, P. K. (1992, September). The perception of speech by infants: What is given by nature, what is gained by experience. Paper presented at the New York Academy of Sciences/Rodin Remediation Academy Conference, New York

Larsen, J., Holen, T., Lundberg, I., \& Odegaard, H. (1990). MRI evaluation of the size and symmetry of the planum temporale in adolescents with developmental dyslexia. Brain \& Language, 39, 289-301. 
Larsen, J. P., Hoien, T., \& OdegaARd, H. (1992). Magnetic resonance imaging of the corpus callosum in developmental dyslexia. Cognitive Neuropsychology, 9, 123-134.

Lehmkuhle, S., Garzia, R. P., Turner, L., Hash, T., \& Baro, J. A (1993). A defective visual pathway in children with reading disability. New England Journal of Medicine, 382, 989-996.

LenNARTZ, R. C., \& WeINBERGER, N. M. (1992). Frequency selectivity is related to temporal processing in parallel thalamocortical auditory pathways. Brain Research, 583, 81-92.

LIBERMAN, I. Y. (1983). A language-oriented view of reading and its disabilities. In H. Myklebust (Ed.), Progress in learning disabilities (Vol. 5, pp. 81-101). New York: Grune \& Stratton.

LIBERMAN, I. Y, (1989). Phonology and beginning reading revisited. In C. von Euler, I. Lundberg, \& G. Lennerstrand (Eds.), Brain and reading (pp. 207-220). New York: Stockton Press.

LiBerMan, I. Y., \& ShANKWEILER, D. (1985). Phonology and the problems of learning to read and write. Remedial \& Special Education, 6, 8-17.

Livingstone, M. S., \& Hubel, D. H. (1987). Psychophysical evidence for separate channels for the perception of form, color, movement, and depth. Journal of Neuroscience, 7, 3416-3468.

Livingstone, M. S., Rosen, G. D., Drislane, F. W., \& Galaburda, A. M. (1991). Physiological and anatomical evidence for a magnocellular defect in developmental dyslexia. Proceedings of the National Academy of Sciences, 88, 7943-7947.

Lovegrove, W. [J.], \& HeddLE, M. (1980). Visual persistence as a function of spatial frequency and age. Perception, 9, 529-532.

Lovegrove, W. J., Heddle, M., \& Slaghuis, W. (1980). Reading disability: Spatial frequency specific deficits in visual information store. Neuropsychologia, 18, 111-115.

Lovegrove, W. [J.], Martin, F., \& Slaghuis, W. (1986). A theoretical and experimental case for a visual defict in specific reading disability. Cognitive Neuropsychology, 3, 225-267.

Lovegrove, W. [J.], Pepper, K., Martin, F., Mackenzie, B., \& McNiCOL, D. (1989). Phonological recoding, memory processing and visual deficits in specific reading disability. In D. Vickers \& P. I. Smith (Eds.), Human information processing: Measures, mechanisms and models (pp. 65-79). Amsterdam: Elsevier, North-Holland.

Lovegrove, W. [J.], Slaghuis, W., Bowling, A., Nelson, P., \& GEEVES, E. (1986). Spatial frequency processing and the prediction of reading ability: A preliminary investigation. Perception \& Psychophysics, 40, 440-444.

LOVETT, M. W. (1984). A developmental perspective on reading dysfunction: Accuracy and rate criteria in the subtyping of dyslexic children. Brain \& Language, 22, 67-91.

LOVETT, M. W. (1987). A developmental approach to reading disability: Accuracy and speed criteria of normal and deficient reading skill. Child Development, 58, 234-260.

Ludlow, C. L., Cudahy, E. A., Bassich, C., \& Brown, G. L. (1983). Auditory processing skills of hyperactive, language-impaired and reading-disabled boys. In E. Z. Lasky \& J. Katz (Eds.), Central auditory processing disorders (pp. 163-184). Baltimore: University Park Press

LUNDBERG, I., \& HoIEN, T. (1989). Phonemic deficits: A core symptom of developmental dyslexia? Irish Journal of Psychology, 10, 579-592.

LYON, G. R. (1985). Educational validation studies of learning disability subtypes. In B. P. Rourke (Ed.), Neuropsychology of learning disabilities: Essentials of subtype analysis (pp. 228-253). New York: Guilford Press.

MANN, V. A. (1984). Longitudinal prediction and prevention of early reading difficulty. Annals of Dyslexia, 34, 117-136.

MANN, V. A. (1993). Phoneme awareness and future reading ability. Journal of Learning Disabilities, 26, 259-269.

MANN, V. A., \& BRADY, S. (1988). Reading disability: The role of language deficiencies. Journal of Consulting \& Clinical Psychology, 56, 811-816.

ManN, V. A., Liberman, I. Y., \& Shankweiler, D. (1980). Children's memory for sentences and word strings in relation to reading ability. Memory \& Cognition, 8, 329-335.

Martin, F., \& Lovegrove, W. J. (1988). Uniform-field flicker masking in control and specifically-disabled readers. Perception, 17, 203-214.
MASON, M. (1980). Reading ability and the encoding of item and location information. Journal of Experimental Psychology: Human Perception \& Performance, 6, 89-98.

MaY, J. G., Williams, M. C., \& DunlaP, W. P. (1988). Temporal order judgements in good and poor readers. Neuropsychologia, 26, 917-924.

MCCroskey, R. L., \& Kidder, H. C. (1980). Auditory fusion among learning disabled, reading disabled, and normal children. Journal of Learning Disabilities, 13, 18-25.

McGivern, R. F., Berka, C., Languis, M. L., \& Chapman, S. (1991). Detection of deficits in temporal pattern discrimination using the Seashore Rhythm Test in young children with reading impairments. Journal of Learning Disabilities, 24, 58-62.

Merzenich, M. M., Schreiner, C., Jenkins, W., \& Wang, X. (1993). Neural mechanisms underlying temporal integration, segmentation, and input sequence representation: Some implications for the origin of learning disabilities. In P. Tallal, A. M. Gallaburda, R. R. Llinás, \& C. von Euler (Eds.), Temporal information processing in the nervous system: Special reference to dyslexia and dysphasia (Annals of the New York Academy of Sciences, Vol. 682, pp. 1-22). New York: New York Academy of Sciences.

Morrongiello, B. A., \& Trehub, S. E. (1987). Age-related changes in auditory temporal perception. Journal of Experimental Child Psychology, 44, 413-426.

NicOLSON, R. I., \& FAwCETT, A. J. (1990). Automaticity: A new framework for dyslexia research? Cognition, 35, 159-182.

NiCOLSON, R. I., \& FAwCETT, A. J. (1993). Children with dyslexia automatise temporal skills more slowly. In P. Tallal, A. M. Gallaburda, R. R. Llinás, \& C. von Euler (Eds.), Temporal information processing in the nervous system: Special reference to dyslexia and dysphasia (Annals of the New York Academy of Sciences, Vol. 682, pp. 387389). New York: New York Academy of Sciences.

O’Connor, P. D., Sofo, F., Kendall, L., \& Olsen, G. (1990). Reading disabilities and the effects of colored filters. Journal of Learning Disabilities, 23, 597-603, 620 .

Ojemann, G., \& Mateer, C. (1979, September 28). Human language cortex: Localization of memory, syntax, and sequential motorphoneme identification systems. Science, 205, 1401-1403.

Olson, R. K., Davidson, B. J., Kliegl, R., \& Davies, S. E. (1984). Development of phonetic memory in disabled and normal readers. Journal of Experimental Child Psychology, 37, 187-206.

Olson, R. K., ForsBerg, H., \& WISE, B. (1994). Genes, environment, and the development of orthographic skills. In V. W. Berginger (Ed.), The varieties of orthographic knowledge I: Theoretical and developmental issues (pp. 27-71), Dordrecht: Kluwer.

Olson, R. [K.], Wise, B., ConNers, F., RaCk, J., \& Fulker, D. (1989). Specific deficits in component reading and language skills: Genetic and environmental influences. Journal of Learning Disabilities, 22, 339-348.

O’NEILL, G., \& STANLEY, G. (1976). Visual processing of straight lines in dyslexic and normal children. British Journal of Educational Psychology, 46, 323-327.

Pennington, B. F., \& Smith, S. D. (1988). Genetic influences on learning disabilities: An update. Journal of Consulting \& Clinical Psychology, 56, 817-823.

Phillips, D. P., \& Farmer, M. E. (1990). Acquired word deafness, and the time frame of processing in the primary auditory cortex. Behavioural Brain Research, 40, 85-94.

PoIzNER, H., \& TALLAL, P. (1987). Temporal processing in deaf signers. Brain \& Language, 30, 52-62.

RACK, J. (1985). Orthographic and phonetic coding in developmental dyslexia. British Journal of Psychology, 76, 325-340.

RaPiN, I., \& Allen, D. A. (1988). Syndromes in developmental dysphasia and adult aphasia. In F. Plum (Ed.), Language, communication and the brain (pp. 57-75). New York: Raven Press.

RAviZZA, R. J., \& BELMORE, S. M. (1978). Auditory forebrain: Evidence from anatomical and behavioral experiments involving human and animal subjects. In R. B. Masterton (Ed.), Handbook of behavioral neurobiology: Vol. 1. Sensory integration (pp. 459-501). New York: Plenum.

RAYNER, K. (1975). The perceptual span and peripheral cues in reading. Cognitive Psychology, 7, 65-81. 
Rayner, K., \& Pollatsek, A. (1987). Eye movements in reading: A tutorial review. In M. Coltheart (Ed.), Attention and performance XII: The psychology of reading (pp. 327-362). Hove, U.K.: Erlbaum.

REED, M. A. (1989). Speech perception and the discrimination of brief auditory cues in reading-disabled children. Journal of Experimental Child Psychology, 48, 270-292.

RIPPS, H., \& WEALE, R. A. (1976). Temporal analysis and resolution. In H. Davison (Ed.), The eye (2nd ed., pp. 185-194). New York: Academic Press.

Robin, D. A., Tomblin, J. B., Kearney, A., \& Hug, L. N. (1989). Auditory temporal pattern learning in children with speech and language impairments. Brain \& Language, 36, 604-613.

Robinson, G. L. W., \& ConWay, R. N. F. (1990). The effects of Irlen colored lenses on students' specific reading skills and their perception of ability: A 12-month validity study. Journal of Learning Disabilities, 23, 589-596.

SATZ, P., \& MorRIs, R. (1981). Learning disability subtypes: A review. In F. J. Pirozzolo \& M. C. Wittrock (Eds.), Neuropsychological and cognitive processes in reading (pp. 109-141). New York: Academic Press

SCARBOROUGH, H. S. (1989). Prediction of reading disability from familial and individual differences. Journal of Educational Psychology, 81, 101-108.

SCARBorough, H. S. (1990). Very early language deficits in dyslexic children. Child Development, 61, 1728-1743.

SChWARTZ, J., \& TAllal, P. (1980, March 21 ). Rate of acoustic change may underlie hemispheric specialization for speech perception. Science, 207, 1380-1381.

Segalowitz, S., Wagner, W. J., \& Menna, R. (1992). Lateral versus frontal ERP predictors of reading skill. Brain \& Language, 20, 85-103.

Seidenberg, M. S., \& MANis, F. R. (1994, November). On the bases of the "surface" and "phonological" subtypes of developmental dyslexia. Paper presented at the meeting of the Psychonomic Society, St. Louis.

Seidenberg, M. S., \& McClelland, J. L. (1989). A distributed, developmental model of word recognition and naming. Psychological Review, 96, 523-568.

SEymour, P. H. K., \& EldER, L. (1986). Beginning reading without phonology. Cognitive Neuropsychology, 3, 1-36.

Shapiro, K. L., Ogden, N., \& Lind-Blad, F. (1990). Temporal processing in dyslexia. Journal of Learning Disabilities, 23, 99-107.

Share, D. L., Jorm, A. F., Maclean, R., \& Matthews, R. (1984) Sources of individual differences in reading acquisition. Journal of Educational Psychology, 76, 1309-1324.

Share, D. L., \& Silva, P. A. (1987). Language deficits and specific reading retardation: Cause or effect? British Journal of Disorders of Communication, 22, 219-226.

Siegel, L. S., \& Linder, B. A. (1984). Short-term memory processes in children with reading and learning disabilities. Developmental Psy chology, 20, 200-207.

Slaghuis, W. L., \& Lovegrove, W. J. (1985). Spatial-frequencydependent visible persistence and specific reading disability. Brain \& Cognition, 4, 219-240.

Slaghuis, W. L., \& Lovegrove, W. J., \& Freestun, J. (1992). Letter recognition in peripheral vision and metacontrast masking in dyslexic and normal readers. Clinical Vision Science, 7, 53-65.

SnOWLing, M. [J.] (1987). Dyslexia: A cognitive developmental perspective. Oxford, U.K.: Basil Blackwell.

Snowling, M. J. (1991). Developmental reading disorders. Journal of Child Psychology \& Psychiatry, 32, 49-77.

Snowling, M. [J.], Stackhouse, J., \& Rack, J. (1986). Phonological dyslexia and dysgraphia-A developmental analysis. Cognitive Neuropsychology, 3, 309-339.

SNOWling, M. [J.], vaN Wagtendonk, B., \& StafFord, C. (1988). Object-naming deficits in developmental dyslexia. Journal of Research in Reading, 11, 67-85.

SOlAN, H. A. (1990). An appraisal of the Irlen technique of correcting reading disorders using tinted overlays and tinted lenses. Journal of Learning Disabilities, 23, 621-623, 626

Solman, R. T., \& MAY, J. G. (1990). Spatial localization discrepancies A visual deficiency in poor readers. American Journal of Psychology, 103, 243-263.

Stanley, G., \& Hall, R. (1973). A comparison of dyslexics and nor- mals in recalling letter arrays after brief presentation. British Journal of Education Psychology, 43, 301-304.

Stanovich, K. E. (1980). Toward an interactive-compensatory model of individual differences in the development of reading fluency. Read ing Research Quarterly, 16, 32-71.

STANOVICH, K. [E.] (1986a). Cognitive processes and the reading problems of learning-disabled children: Evaluating the assumption of specificity. In J. Torgesen \& B. Wong (Eds.), Psychological and educational perspectives on learning disabilities (pp. 87-131). New York: Academic Press.

Stanovich, K. E. (1986b). Matthew effects in reading: Some consequences of individual differences in the acquisition of literacy. Reading Research Quarterly, 21, 360-406.

STANOVICH, K. E. (1988a). Explaining the differences between the dyslexic and the garden-variety poor reader: The phonological-core variable difference model. Journal of Learning Disabilities, 21, 590-604.

Stanovich, K. E. (1988b). The right and wrong places to look for the cognitive locus of reading disability. Annals of Dyslexia, 38, 154-177.

Stanovich, K. E., Cunningham, A. E., \& Cramer, B. B. (1984). Assessing phonological awareness in kindergarten children: Issues of task comparability. Journal of Experimental Child Psychology, 38, 175-190

Stanovich, K. E., West, R. F., \& Feeman, D. J. (1981), A longitudinal study of sentence context effects in second-grade children: Tests of an interactive-compensatory model. Journal of Experimental Child Psychology, 32, 185-199.

Stark, R. E., Bernstein, L. E., Condino, R., Bender, M., Tallal, P. $\&$ CATTS, H. (1984). Four-year follow-up study of language-impaired children. Annals of Dyslexia, 34, 49-68.

Stark, R. E., \& Tallal, P. (1981). Perceptual and motor deficits in language-impaired children. In R. W. Keith (Ed.), Central auditory and language disorders in children (pp. 121-144). Houston: CollegeHill Press.

Stark, R. E., Tallal, P., \& Mellits, E. D. (1985). Expressive language and perceptual and motor abilities in language-impaired children. Human Communication Canada, 9, 23-28.

Stefanatos, G. A., Green, G. G. R., \& Ratcliff, G. G. (1989). Neurophysiological evidence of auditory channel anomalies in developmental dysphasia. Archives of Neurology, 46, 871-875.

StudderT-Kennedy, M., \& Shankweiler, D. (1970). Hemispheric specialization for speech perception. Journal of the Acoustical Society of America, 48, 579-594.

TALLAL, P. (1976). Rapid auditory processing in normal and disordered language development. Journal of Speech \& Hearing Research, 19. $561-571$.

TALLAL, P. (1978). An experimental investigation of the role of auditory temporal processing in normal and disordered language development. In A. Caramazza \& E. B. Zurif (Eds.), Language acquisition and language breakdown: Parallels and divergencies (pp. 25-61). Baltimore: Johns Hopkins University Press.

TALLAL, P. (1980). Auditory temporal perception, phonics, and the reading disabilities in children. Brain \& Language, 9, 182-198.

Tallal, P. (1984). Temporal or phonetic processing deficit in dyslexia? That is the question. Applied Psycholinguistics, 5, 167-169.

TALLAL, P. (1985). Neuropsychological research approaches to the study of central auditory prcoessing. Human Communication Canada, 9, 17-22.

TALLAL, P. (1988). Developmental language disorders: Part 1-Definition. Human Communication Canada, 12, 7-22.

TALLAL, P., \& CURTISS, S. (1990). Neurological basis of developmental language disorders. In A. Rothenberger (Ed.), Brain and behavior in child psychiatry (pp. 205-216). New York: Springer-Verlag.

TAllal, P., \& PierCY, M. (1973). Developmental aphasia: Impaired rate of non-verbal processing as a function of sensory modality. Neuropsychologia, 11, 389-398.

Tallal, P., \& PierCy, M. (1975). Developmental aphasia: The perception of brief vowels and extended stop consonants. Neuropsychologia, 13, 69-74.

Tallal, P., Sainburg, R. L., \& Jernigan, T. (1991). The neuropathology of developmental dysphasia: Behavioral, morphological, and physiological evidence for a pervasive temporal processing disorder. Reading \& Writing, 3, 363-377

Tallal, P., \& StaRK, R. E. (1982). Perceptual/motor profiles of read- 
ing impaired children with or without concomitant oral language deficits. Annals of Dyslexia, 32, 163-176.

Tallal, P., Stark, R. [E.], Kallman, C., \& Mellits, D. (1981). A reexamination of some nonverbal perceptual abilities of languageimpaired and normal children as a function of age and sensory modality. Journal of Speech \& Hearing Research, 24, 351-357.

Tallal, P., Stark, R. E., \& Mellits, E. D. (1985). Identification of language-impaired children on the basis of rapid perception and production skills. Brain \& Language, 25, 314-322.

Tallal, P., Townsend, J., Curtiss, S., \& Wulfeck, B. (1991). Phenotypic profiles of language-impaired children based on genetic/family history. Brain \& Language, 41, 81-95.

ThatCHER, R. W. (1980). Neurolinguistics: Theoretical and evolutionary perspectives. Brain \& Language, 11, 235-260.

TORGESEN, J. K. (1985). Memory processes in reading-disabled children. Journal of Learning Disabilities, 18, 350-357.

TZENG, O. J. L., \& WANG, W. S.-Y. (1984). Search for a common neurocognitive mechanism for language and movements. American Journal of Physiology, 246, R904-R911.

UNDERWOOD, G., \& BOOT, D. (1986). Hemispheric asymmetries in developmental dyslexia: Cerebral structure or attentional strategies? Journal of Reading Behavior, 18, 219-228.

Vellutino, F. R. (1987, March). Dyslexia. Scientific American, 256, $34-41$

Vellutino, F. R., \& SCANLon, D. M. (1987). Phonological coding, phonological awareness, and reading ability: Evidence from a longitudinal and experimental study. Merrill-Palmer Quarterly, 33, 321-363.

Vellutino, F. R., Steger, J. A., Kaman, M., \& De Setto, L. (1975) Visual form perception in deficient and normal readers as a function of age and orthographic-linguistic familiarity. Cortex, 11, 22-30.

WAGNER, R. K. (1986). Phonological processing abilities and reading: Implications for disabled readers. Journal of Learning Disabilities, 19, 623-630.

WAGNER, R. K., \& TORGESEN, J. K. (1987). The nature of phonological processing and its causal role in the acquisition of reading skills. $P s y$ chological Bulletin, 101, 192-212.

WATKINS, R. V. (1990). Processing problems and language impairment in children. Topics in Language Disorders, 11, 63-72

WATSON, B. U. (1992). Auditory temporal acuity in normally achieving and learning-disabled college students. Journal of Speech \& Hearing Research, 35, 148-156.

WERKER, J. (1989). Becoming a native listener. American Scientist, 77, 54-59.

Werker, J. F., Bryson, S. E., \& Wassenberg, K. (1989). Toward understanding the problem in severely disabled readers: Part II. Consonant errors. Applied Psycholinguistics, 10, 13-30.

WERKER, J. F., \& TEES, R. C. (1987). Speech perception in severely disabled and average reading children. Canadian Journal of Psychology, 41, 48-61.

Werner, L. A., Marean, G. C., Halpin, C. F., SPetner, N. B., \& GillenWATER, J. M. (1992). Infant auditory temporal acuity: Gap detection. Child Development, 63, 260-272.

WICKELGREN, W. A. (1979). Cognitive psychology. Englewood Cliffs, NJ: Prentice-Hall

Williams, M., \& LeCluyse, K. (1990). Perceptual consequences of a temporal processing deficit in reading-disabled children. Journal of the American Optometric Association, 61, 111-121.

Winters, R. L., PATterson, R., \& SHONTZ, W. (1989). Visual persistence and adult dyslexia. Journal of Learning Disabilities, 22, 641-645.

WOLF, M. (1986). Rapid alternating stimulus naming in the developmental dyslexias. Brain \& Language, 27, 360-379.

WOLF, M. (1991). Naming speed and reading: The contribution of the cognitive neurosciences. Reading Research Ouarterly, 26, 123-141.

WOLF, M., \& OBREGON, M. (1992). Early naming deficits, developmental dyslexia, and a specific deficit hypothesis. Brain \& Language, $\mathbf{4 2}$, 219-247.

WolfF, P. H., Cohen, C., \& DraKe, C. (1984). Impaired motor timing control in specific reading retardation. Neuropsychologia, 22, 587-600

WolfF, P. H., Michel, G. F., Ovrut, M., \& DraKe, C. (1990). Rate and timing precision of motor coordination in developmental dyslexia. Developmental Psychology, 26, 349-359.
Wood, F., Flowers, L., Buchsbaum, M., \& Tallal, P. (1991). Investigation of abnormal left temporal functioning in dyslexia through rCBF, auditory evoked potentials, and positron emission tomography Reading \& Writing, 3, 379-393.

ZuRIF, E. G., \& CARson, G. (1970). Dyslexia in relation to cerebral dominance and temporal analysis. Neuropsychologia, 8, 351-361.

\section{NOTES}

1. A brief note about the use of the words phonetic, phonemic, and phonological is warranted. A phonetic representation of sounds would instantiate the surface structure of phones in speech. A phoneme refers to a group of (phonetically different) sounds that are considered to be essentially the same vocal sound, and are represented the same way. Thus the $s$ in cats (which occurs after an unvoiced consonant) and the $s$ in dogs (which occurs after a voiced consonant) are phonemically the same but phonetically different (Liberman, 1983). Phonology refers to the science of vocal sounds, and is commonly thought of as the knowledge of grapheme-phoneme (letter-sound) correspondences (Seymour \& Elder, 1986). In this article, we have made two assumptions. First, because phonetic discriminations are necessarily more complex and subtle than phonemic discriminations, we have assumed that a child who has difficulty distinguishing phonemes would also have difficulty with phonetic differences. We therefore use the term phonemic deficit throughout to refer to such difficulties. Second, we have assumed for the present purposes that a phonemic deficit is a sufficient (if not necessary) cause of impaired phonological processing.

2. Stanovich derived the term "Matthew effect" from verse 29 of chapter 25 of the Book of Matthew in the New Testament, which reads: "For unto every one that hath shall be given and he shall hath abundance: but from him that hath not shall be taken away even that which he hath."

3. A PsychLit computer search located all listed studies under the search terms sequential or temporal processing and dyslexia or reading disability, or variations of these terms. All available relevant studies cited in the located studies were reviewed and all appropriate current available journals were also searched. Many of the studies reviewed were excluded because the "sequential" or "temporal" processing involved did not meet our temporal criteria for inclusion in the classification scheme (e.g., see some of the studies described for comparison in the section on sequence matching/discrimination). Studies that involved only normal readers and not reading-disabled subjects were also excluded.

4. Tasks requiring separation of events over time that involve many identical stimuli are known as auditory flutter or visual flicker tasks. It might be argued that flicker and flutter tasks involve more complex instances of numerosity judgments (visual flash fusion occurs at ISIs of approximately 16-20 msec, similar to tasks involving two flashes [Ripps $\&$ Weale, 1976]). However, it is not clear that such tasks fall within the scope of our discussion, because it is possible that when many events occur close together, decisions might be based on a detection of change in intensity over time. Dyslexics may well show the same deficits on flicker and flutter tasks as they do on stimulus individuation tasks (and our reading of Tallal's hypothesis predicts that they should). However, because such tasks may be solved on the basis of a quality other than discreteness of events, we have not included them in our review. For a discussion of the performance of dyslexics on flicker tasks, the reader is referred to Martin and Lovegrove (1988)

5. No differences were found between the performances of languageimpaired children and controls on Tallal's tasks by Aram and Ekelman (1988). However, all the language-impaired children in this study were exhibiting higher level language and learning problems following unilateral brain lesions, and all had been developing normally premorbidly. They were thus quite a different population from the developmentally language-impaired children studied by Tallal $(1976,1978)$.

6. Unfortunately, Ludlow et al. (1983) did not test a group of children who were specifically reading impaired but not hyperactive. Had they done so, then on the basis of our review, we would expect such a group, like the language-impaired group, to be impaired on both temporal processing tasks, but not the vigilance task.

7. Two classes of cells transmit information about stimuli in the visual system: parvocellular neurons (equivalent to $\mathrm{x}$ cells in the cat) respond to sustained stimuli, and magnocellular neurons (equivalent to y cells in 
the cat) respond to the onset and offset of stimuli (transience). Magnocellular neurons are more dominant in peripheral vision, and parvocellular neurons are more dominant in central, or foveal, vision. The more rapidly responding transient system is more sensitive to high as opposed to low temporal frequencies and to low as opposed to high spatial frequencies; the reverse is true for the slower responding sustained system (Livingstone \& Hubel, 1987). Moreover, the two systems are mutually inhibitory (Breitmeyer, 1980). Note that the current understanding of the visual system surpasses that of the auditory system. It has yet to be shown that the transient and sustained mechanisms in the visual system have parallels in the auditory system.

8. The use of colored filters or lenses (Irlen lenses) has been advocated by some investigators for use with reading-disabled children on the grounds that these may ameliorate subtle visual deficits ("scotopic sen- sitivity") that affect the ability to read (see, e.g., studies by O'Connor, Sofo, Kendall, \& Olsen, 1990, and Robinson \& Conway, 1990; and appraisals by Solan, 1990, and Hoyt, 1990). However, this research must be considered preliminary, and although there are some intriguing suggestions that colored lenses might be helpful for some reading-disabled children, there is not sufficient evidence to indicate whether this is in fact the case, or for which children the lenses might be useful, or what mechanisms are involved if they are useful. There is certainly insufficient evidence at this time to link the types of deficits that might be involved in "scotopic sensitivity" and the types of visual deficits discussed in this paper.

(Manuscript received October 25, 1993; revision accepted for publication January 25, 1995.) 